\title{
The erosion performance of cold spray deposited metal matrix composite coatings with subsequent friction stir processing
}

\author{
Tom Peat ${ }^{\mathrm{a}}$, Alexander Galloway ${ }^{\mathrm{a}}$, Athanasios Toumpis ${ }^{\mathrm{a}}$, Philip McNutt $^{\mathrm{b}}$, Naveed lqbal ${ }^{\mathrm{c}}$ \\ ${ }^{a}$ Department of Mechanical \& Aerospace Engineering, University of Strathclyde, James Weir \\ Building, 75 Montrose Street, Glasgow G1 1XJ, United Kingdom \\ ${ }^{\mathrm{b}}$ TWI Ltd, Granta Park, Cambridge, CB21 6AL, United Kingdom \\ ${ }^{\text {C} T W I ~ T e c h n o l o g y ~ C e n t r e, ~ W a l l i s ~ W a y, ~ C a t c l i f f, ~ R o t h e r h a m, ~ S 60 ~ 5 T Z, ~ U n i t e d ~ K i n g d o m ~}$
}

\begin{abstract}
This study forms an initial investigation into the development of SprayStir, an innovative processing technique for generating erosion resistant surface layers on a chosen substrate material. Tungsten carbide - cobalt chromium, chromium carbide - nickel chromium and aluminium oxide coatings were successfully cold spray deposited on AA5083 grade aluminium. In order to improve the deposition efficiency of the cold spray process, coatings were codeposited with powdered AA5083 using a twin powder feed system that resulted in thick (>300 $\mu \mathrm{m})$ composite coatings. The deposited coatings were subsequently friction stir processed to embed the particles in the substrate in order to generate a metal matrix composite (MMC) surface layer. The primary aim of this investigation was to examine the erosion performance of the SprayStirred surfaces and demonstrate the benefits of this novel process as a surface engineering technique. Volumetric analysis of the SprayStirred surfaces highlighted a drop of approx. $40 \%$ in the level of material loss when compared with the cold spray deposited coating prior to friction stir processing. Micro-hardness testing revealed that in the case of WC-CoCr reinforced coating, the hardness of the SprayStirred material exhibits an increase of approx. $540 \%$ over the unaltered substrate and $120 \%$ over the as-deposited composite coating. Microstructural examination demonstrated that the increase in the hardness of the MMC aligns with the improved dispersion of reinforcing particles throughout the aluminium matrix.
\end{abstract}

\section{Keywords}

SprayStir; Friction stir processing; Cold spray; Metal matrix composite; Slurry erosion; Cermet 


\section{Introduction}

Cold gas dynamic spraying (cold spray) is a low temperature coating technique that is used to deposit powder feedstock particles on a variety of substrate materials [1,2]. Conventional spraying processes such as high velocity oxy-fuel (HVOF) [3] or plasma spraying [3] can result in the complete or partial melting of the feedstock powder particles. As a consequence, excessive residual stresses caused by contraction of particles during solidification are present within the coating [4]. Additionally, the deposited material may suffer from oxidation where spraying is undertaken without an appropriate shielding gas [5]. The high temperatures in these processes can also alter the constituent phases of the feedstock material resulting in a coating containing potentially undesirable phases $[5,6]$.

In contrast, the bonding mechanism in cold spray results from the acceleration of powder particles to supersonic velocities using a de'Laval nozzle and a compressible carrier gas such as nitrogen or helium [2]. The significant kinetic energy of the particles as they impact the substrate causes them to plastically deform, producing splats [7] on the surface of the substrate. Layers of adjoining splats bond together to form the coating layer. By maintaining the particle temperature below the solidus, any undesirable phase transformations are avoided, hence the constituent phases of the coating layer reflect those that form the feedstock powder particles. Coatings produced via cold spray exhibit a work hardened structure due to the extensive deformation of impinged particles [2]. Furthermore, existing research [8] reports the generation of compressive residual stresses within the aluminium coating which has been shown to enhance the fatigue performance.

Developed in the mid-1980's, cold spray has been the subject of extensive research in the areas of component repair and coating production [2,9]. The low particle temperatures make this process suitable for the deposition of material on aluminium and magnesium substrates. More recently however, studies have investigated the deposition of metal matrix composite (MMC) coatings in an attempt to produce erosion resistant surfaces [10,11]. The cold spraying of suitable material is inherently difficult due to the limited deformability of the powder particles at the temperatures experienced during the cold spray process. A study by Seo et al. [12], demonstrated that, instead of adhering to the substrate, the spraying of cermet particles can result in a grit blasting effect on the surface of the substrate.

Despite this, studies have shown that the deposition of erosion resistant material is achievable with appropriate parameter development. Couto et al. [11] were able to produce a coating layer comprising tungsten carbide particles when deposited with a ductile metallic 
binder. However, the limited deformability of the cermets restricted the build-up of a thick ( $>100$ $\mu \mathrm{m})$ coating. In the study by Couto et al. [11], the metallic binder was incorporated by using an agglomerated, sintered powder comprising tungsten carbides, cobalt and chromium. This method of adding a binding material is limited to certain material combinations and the powders must be produced in advance of the cold spray process. The addition of a metallic binder can also be achieved by mixing ceramic and binder powders to the desired ratio prior to spraying. In the current study, two independent powder feeders supplied binder and cermet/ceramic particles simultaneously to the nozzle eliminating the need for powder premixing. This novel approach, referred to as co-deposition, is seen as a potential method of overcoming the inherent difficulties in building up thick $(>300 \mu \mathrm{m})$ coatings comprising cermet or ceramic particles.

Cold spraying adds strength to the binder material in the form of work hardening [13] and grain refinement [14-16]. Severe plastic deformation of the impinged particles produces an elongated grain structure within the deposited material and is accompanied by an associated build-up of dislocations. Binder particles that suffer particularly extensive plastic deformation, such as those that directly impact the surface of the substrate, demonstrate a finer grain structure when compared with the feedstock material. This refinement occurs as a result of the substantial pressures generated upon impact with the substrate causing the recrystallisation of the elongated grains $[15,17,18]$.

The examination of particle reinforced MMCs has been the focus of a number of studies in recent years due to their use in the production of stiff, lightweight components [19]. Investigations have shown that the strengthening effects are linked to the pinning of matrix dislocations by the dispersed reinforcements and is referred to as dispersion strengthening [20]. Existing studies $[13,21-23]$ have revealed that the level of dispersion strengthening relates to the volume fraction of reinforcements and the uniformity of particle distribution. Redsten et al. [24] highlighted the effect of reinforcing particle size on the strengthening effects. The authors [24] found that by reducing the particle size below $0.1 \mu \mathrm{m}$, the level of dispersion strengthening was increased.

The impact of these strengthening mechanisms is highly dependent on the distribution and size of the reinforcing particles [13,20]. A study by Luo et al. [13] investigated the contribution of the various strengthening mechanisms to the measured hardness of a cold spray deposited pcBN/NiCrAl composite coating. Work hardening from the plastic deformation of deposited particles was identified as the most significant mechanism followed by matrix grain refinement and dispersion strengthening [13]. Prior publications $[13,22,25]$ related the hardness 
of MMCs to the dispersal of reinforcing particles in the matrix, with homogenous distribution of fine particles generating superior mechanical properties (yield strength and Young's modulus) [23]. A number of studies have focused on the erosion performance of MMCs [26-28], the findings of which highlight a substantial reduction in the erosion rate of alloys with the addition of particulate reinforcements. In the investigation by Neville et al. [27], the mass loss of the particle reinforced $\mathrm{MMC}$ following exposure to a slurry solution was found to be approx. $90 \%$ less than the as-received substrate material.

Despite the positive results noted by the authors, the cold spray process presents a number of disadvantages. The distribution of the reinforcing particles within a cold spray deposited MMC is difficult to control and can result in regions within the matrix that do not possess any reinforcing material [29]. Moreover, the adhesive strength between the coating and substrate is also a potential cause of poor coating performance [30]. The application of postspray heat treatment is necessary to produce mechanical properties that reflect the bulk material with the as-deposited coating having almost no ductility [31]. Cold spray is also a lineof-sight process and hence limits its use in spraying complex geometries [2].

To mitigate the aforementioned cold spray deposition issues, friction stir processing (FSP) has been applied to the co-deposited cold sprayed MMC coatings to refine and improve the distribution of the reinforcing particles and to remove the defined interface between the coating layer and substrate. FSP is a solid state surface modification technology that makes use of a rotating tool that is plunged into a chosen substrate and traversed along a pre-defined processing path [32]. Contact between the shoulder of the rotating tool and the workpiece generates significant heat and, whilst not sufficient to melt the substrate, causes a softening of the material [33]. The rotational motion of the tool forces this softened material from the leading edge around to the rear of the tool where it is consolidated. FSP has been shown to improve the microstructure and mechanical properties of thermally sprayed coatings [30,34]. Morisada et al. [34] demonstrated the ability of FSP to remove defects such as micro-cracks and porosity from an HVOF sprayed cermet coating comprising tungsten and chromium carbides. The study [34] also reported refinement of the carbide particles and an improved uniformity to their distribution. As a result, the authors [34] recorded a 1.5 times increase in the hardness of the MMC postFSP.

There is limited research $[29,30,35,36]$ that discusses the application of FSP to cold spray deposited coatings. For example, Hodder et al. [29] successfully applied FSP to an asdeposited cold sprayed coating containing $\mathrm{Al}_{2} \mathrm{O}_{3}$ reinforcement particles, but this was not by codeposition and instead made use of an $\mathrm{Al}_{-} \mathrm{Al}_{2} \mathrm{O}_{3}$ mixture. The authors discovered that the FSP 
was able to refine and redistribute the reinforcement particles, however, failed to examine the impact of this on the erosion properties of the coating. Similarly, Huang et al. [36] investigated the effect of FSP on AA5056 reinforced with SiC particles. The authors carried out a comprehensive microstructural evaluation of the stirred coating and concluded that the FSP had successfully refined the $\mathrm{SiC}$ particles. In addition, a preliminary wear study revealed that the presence of reinforcement particles had led to an increase in the coefficient of friction through the pinning effect of the distributed fine particles on the Al matrix [36].

The present study examines the effect of FSP on co-deposited MMC coatings. For the purposes of this investigation, the combination of cold spray and FSP will be referred to as "SprayStir". As-deposited and SprayStirred MMCs were evaluated using light optical and scanning electron microscopy. The micro-hardness across the width of the stir zone was examined and compared with the as-deposited material. The erosion performance of the MMC coatings (pre- and post-FSP) was evaluated under slurry erosive conditions and the mechanisms causing the degradation of the coating surface identified through examination of the resulting wear scars.

\section{Methodology}

\subsection{Materials}

Tungsten carbide (WC-CoCr), chromium carbide $\left(\mathrm{Cr}_{3} \mathrm{C}_{2}-\mathrm{NiCr}\right)$ and aluminium oxide $\left(\mathrm{Al}_{2} \mathrm{O}_{3}\right)$ reinforced $\mathrm{MMC}$ coatings were deposited on AA5083 substrate material. These reinforcement particles were selected in order to provide a comprehensive analysis of materials that are typically employed in thermal spraying processes. Specifically, WC-CoCr and $\mathrm{Cr}_{3} \mathrm{C}_{2^{-}}$ $\mathrm{NiCr}$ are agglomerated powders that are used to produce erosion and corrosion resistant coatings respectively. $\mathrm{Al}_{2} \mathrm{O}_{3}$ has also been included in the study as it provides a low cost alternative to the agglomerated powders and is traditionally difficult to deposit without a suitable binder alloy. The three types of reinforcing particles were co-deposited with AA5083 feedstock powder on to $6 \mathrm{~mm}$ thick AA5083 plates. The specific properties of the reinforcing particles are displayed in Table 1.

Table 1. Feedstock powder properties

\begin{tabular}{llllll}
\hline $\begin{array}{l}\text { Coating } \\
\text { Material }\end{array}$ & $\begin{array}{l}\text { Powder } \\
\text { Identification Code }\end{array}$ & $\begin{array}{l}\text { Composition } \\
(\text { wt.\%) }\end{array}$ & $\begin{array}{l}\text { Particle Size } \\
\text { Range }(\mu \mathrm{m})\end{array}$ & $\begin{array}{l}\text { Average Carbide } \\
\text { Size }(\mu \mathrm{m})\end{array}$ & $\begin{array}{l}\text { Nominal Particle } \\
\text { Density }\left(\mathrm{g} / \mathrm{cm}^{3}\right)\end{array}$ \\
\hline WC-CoCr & Woka 3652 & $\begin{array}{l}\mathrm{W}-10 \mathrm{Co}- \\
5.5 \mathrm{C}-4.4 \mathrm{Cr}\end{array}$ & $15-45$ & 1.07 & 5.0 \\
\hline $\mathrm{Cr}_{3} \mathrm{C}_{2}-\mathrm{NiCr}$ & Woka 7202 & $\begin{array}{l}\mathrm{Cr}-20 \mathrm{Ni}- \\
9.6 \mathrm{C}-0.1 \mathrm{Fe}\end{array}$ & $11-45$ & 3.47 & 2.7 \\
\hline
\end{tabular}




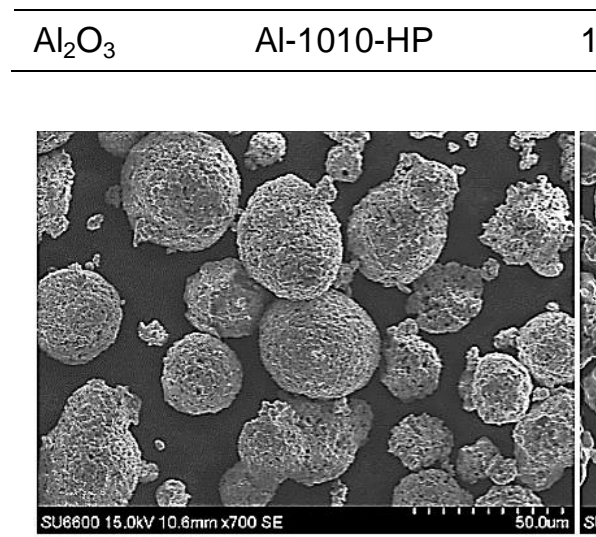

(a)

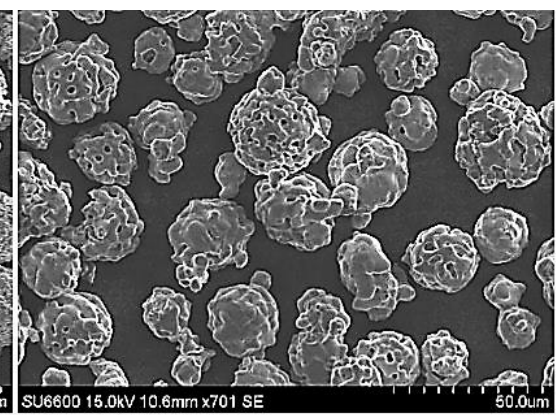

(b)

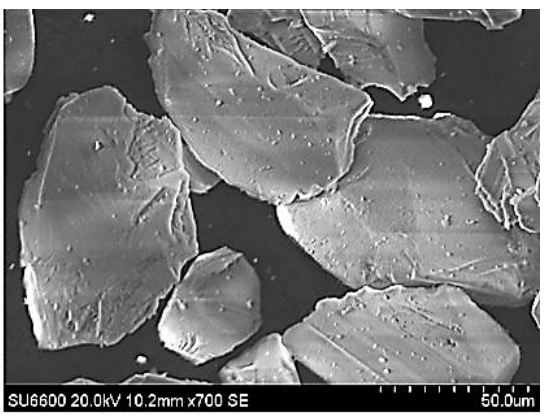

(c)

Fig.1. Scanning electron micrographs of the feedstock powder particles [x700]. a) WC-CoCr; b) $\mathrm{Cr}_{3} \mathrm{C}_{2^{-}}$ $\mathrm{NiCr}$; ) $\mathrm{Al}_{2} \mathrm{O}_{3}$

Fig. 1 highlights the similarities between WC-CoCr and $\mathrm{Cr}_{3} \mathrm{C}_{2}-\mathrm{NiCr}$ particles. Both cermet's are spherical in shape and are similar in size (Table 1). The cermet powders are manufactured through an agglomeration processes which combines carbide particles with a ductile binder. In contrast, the $\mathrm{Al}_{2} \mathrm{O}_{3}$ powder (Fig. 1c) is comprised of pure $\mathrm{Al} 2 \mathrm{O} 3$ particles that are faceted and possess no metallic binder.

\subsection{Coating deposition}

Co-deposition of the three reinforcing particles and binder powder was carried out using a high pressure cold spray system (CGT GmbH Kinetiks 4000) connected to two 4000 series powder feeders (Fig. 2). 


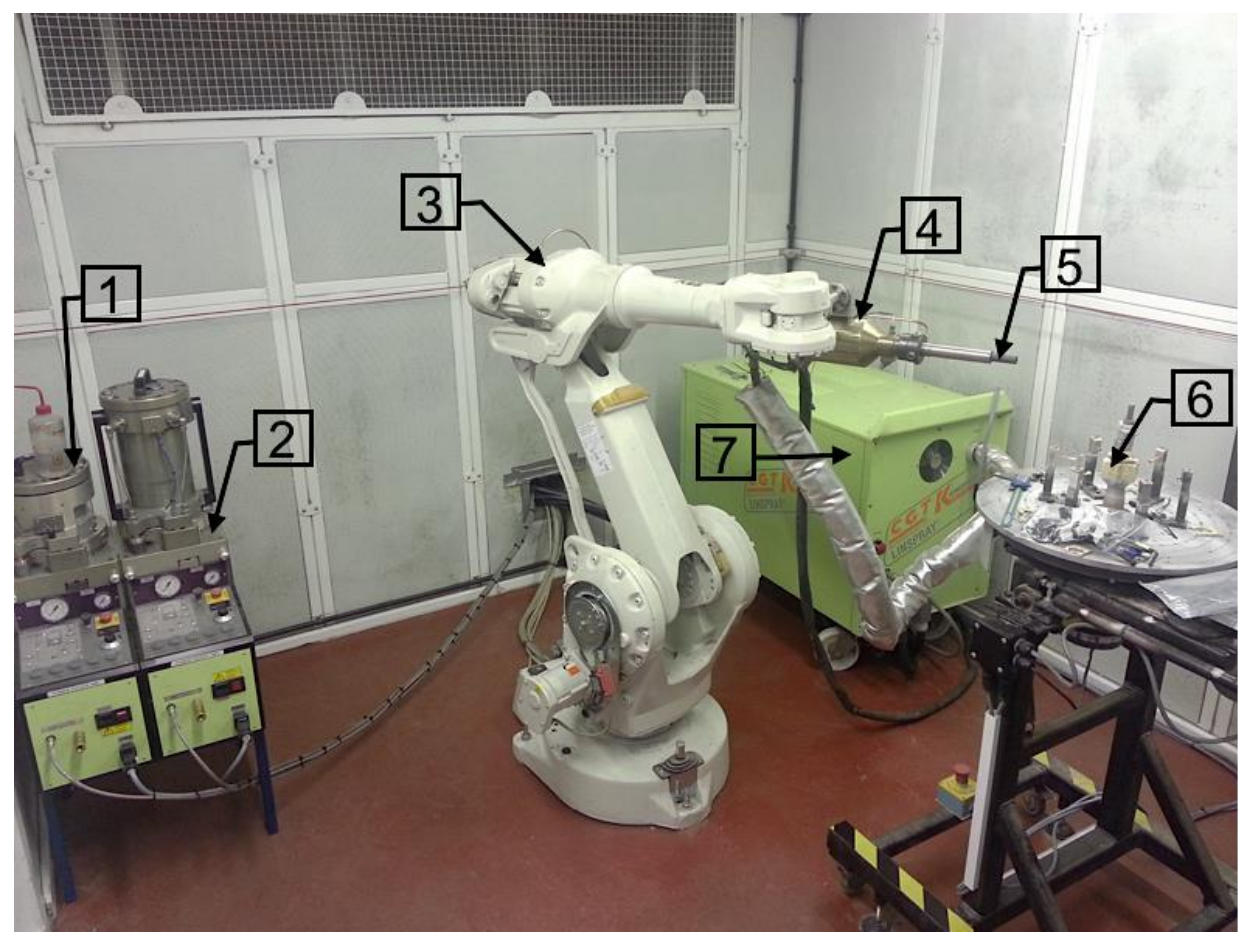

Fig. 2. Image of the cold spray apparatus. (1) Powder feeder 1; (2) Powder feeder 2; (3) Robotic arm; (4) Cold spray gun; (5) Cold spray nozzle; (6) Specimen stage; (7) Gas heater.

In order to improve the repeatability of coating deposition, the cold spray gun was mounted on a robotic arm. A conventional de-Laval nozzle using nitrogen at a temperature of $500^{\circ} \mathrm{C}$ was used to accelerate the powder particles to the necessary velocity to achieve deposition. Following initial parameter development work, powders were co-deposited to a ratio of $40 \%$ binder and $60 \%$ reinforcing particle (vol. \%). This ratio produced a coating thickness in the range $0.38-0.44 \mathrm{~mm}$, following the co-deposition of three layers, (three passes of the cold spray nozzle). All coatings were milled to a standard thickness of $0.3 \mathrm{~mm}$ to provide a uniform surface for the subsequent FSP process.

\subsection{FSP parameter development and setup}

Suitable machine parameters were established for uncoated AA5083 substrate through an iterative parameter development investigation. Tool design and tilt angle were kept constant with the effect of the rotational/traverse speeds and plunge depth examined. The $3^{\circ}$ tilt angle was necessary to prevent chipping of the MMC coating in subsequent processing. The outcome of the study highlighted the plunge depth as having the most significant impact on the resulting processed zone. The parameters that produced a high quality stir zone are presented in Table 2. For the purposes of this study, high quality was identified by the presence of minimal flash [32] and no surface voids. 
Table 2. FSP parameters

\begin{tabular}{llllll}
\hline Tool Type & $\begin{array}{l}\text { Pin Length } \\
(\mathrm{mm})\end{array}$ & $\begin{array}{l}\text { Rotation Speed } \\
(\mathrm{RPM})\end{array}$ & $\begin{array}{l}\text { Traverse Speed } \\
(\mathrm{mm} / \mathrm{min})\end{array}$ & $\begin{array}{l}\text { Plunge } \\
\text { Depth }(\mathrm{mm})\end{array}$ & $\begin{array}{l}\text { Tilt Angle } \\
\left({ }^{\mathrm{O}}\right)\end{array}$ \\
\hline $\begin{array}{l}\text { H13 Concave } \\
\text { shoulder }\end{array}$ & 2 & 600 & 272 & 3.8 & 3 \\
\hline
\end{tabular}

FSP of the MMCs was performed using a TTI precision spindle friction stir welding/processing machine (Fig. 3). The coated aluminium plates were secured to the machine bed using a mechanical clamping system to prevent any movement of the material during processing. The tool was manufactured from $\mathrm{H} 13$ grade tool steel and incorporates a $2 \mathrm{~mm}$ pin with spiral features and a concave shoulder (Fig. 4). In this study, the tool rotated in a clockwise direction.

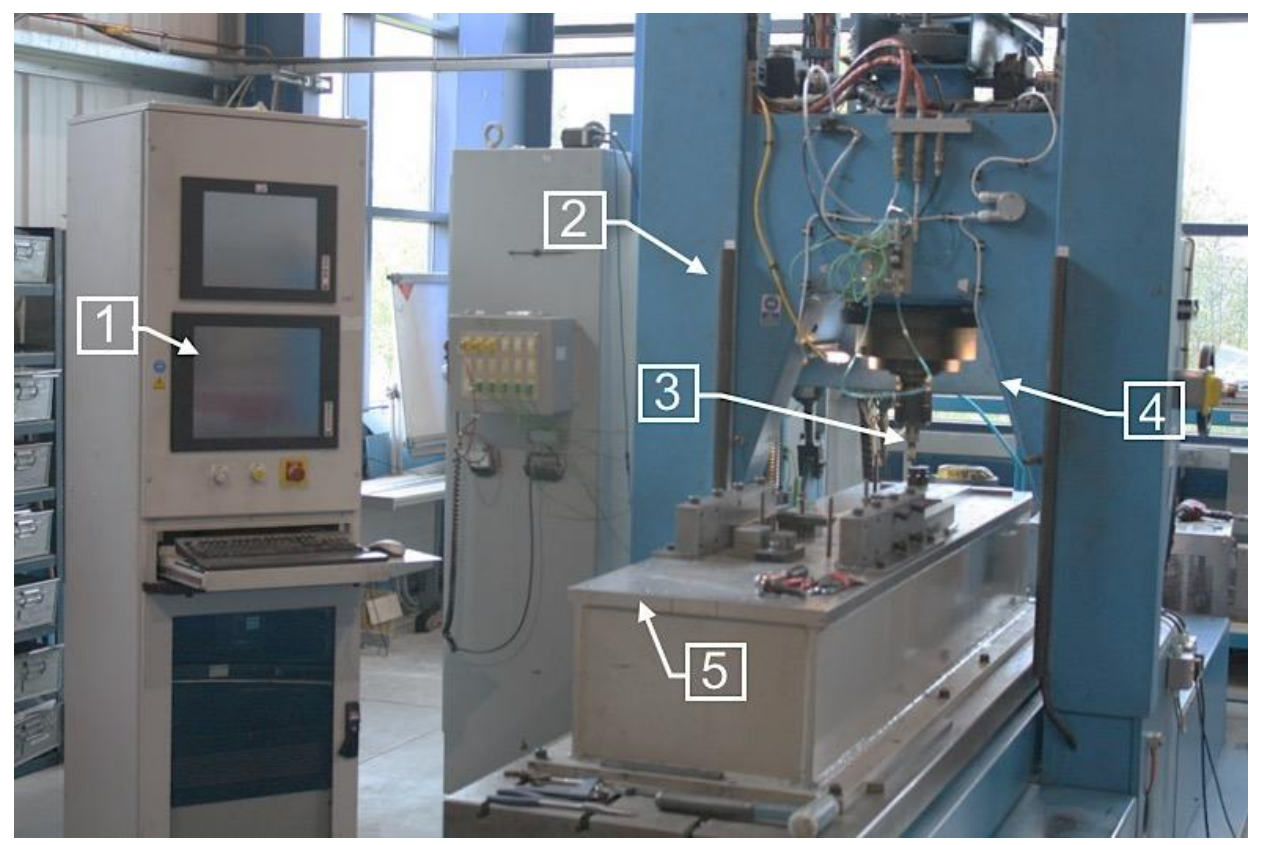

Fig. 3. Image of the FSP equipment. (1) Control cabinet; (2) TTI FSP rig; (3) FSP tool; (4) Rotating spindle; (5) Mobile specimen bed.

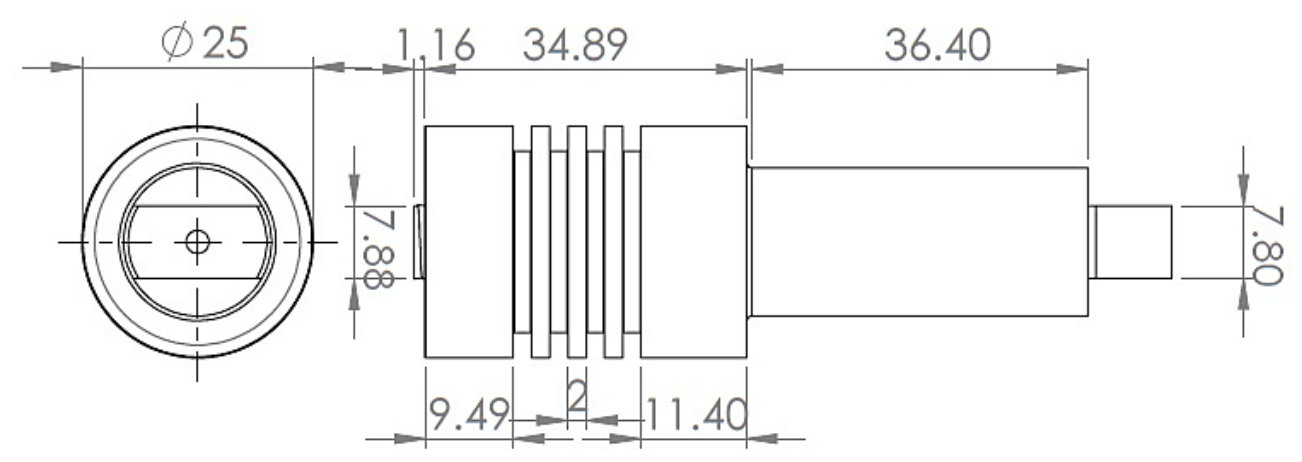

Fig. 4. Two dimensional technical drawing of the H13 FSP tool. 
The FSP process comprised of three distinct stages. First, the tool was plunged into the aluminium plate to a depth of $1.8 \mathrm{~mm}$ and allowed to stabilise. Moving along a straight path, the tool was traversed from the uncoated aluminium on to the coated section of the plate where it continued for a total distance of $100 \mathrm{~mm}$. The retraction of the tool from the plate marked the final stage and the conclusion of the FSP process.

\subsection{Evaluation methods}

\subsubsection{Coating characterisation}

Transverse cross-sections of the stir zone were taken from the processed plate to examine the coating microstructure before and after FSP. A precision cutting wheel (Accutom 5) was used to section the specimens in order to eliminate any cutting damage to the MMC layer. The surface was prepared to a $0.5 \mu \mathrm{m}$ finish using standard metallographic preparation techniques. A macroscopic image showing a cross section view of a typical SprayStirred specimen is displayed in Fig. 5 and depicts the various regions within the stir zone that are discussed throughout this article. The pin region denotes the area of the stir zone through which the tool pin traversed.

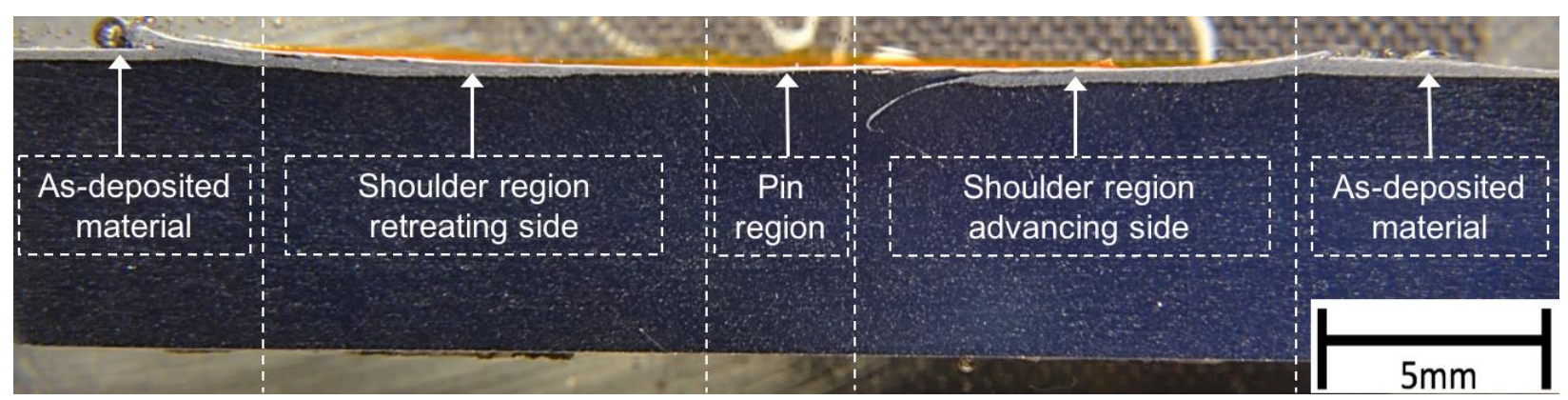

Fig 5. Macroscopic cross section of SprayStirred MMC layer.

An Olympus G51X light optical microscope was used to examine the microstructure of the specimens before and after FSP. The distribution of reinforcing particles within the aluminium matrix was identified using electron micrographs produced by a Hitachi S-3700 series SEM. Energy dispersive spectroscopy (EDS) using Oxford Instruments INCA software mapped the positions of the constituent elements and indicated the dispersion of reinforcing particles throughout the aluminium matrix. Image analysis software was used to quantify the reinforcing particle content for each MMC before and after FSP. Three micrographs were examined for each specimen to determine the average reinforcing particle content.

Micro-hardness values were measured across the width of the stir zone and in the asdeposited MMCs. The results were analysed to determine the change in average hardness following the application of FSP, as well as the average hardness in the regions depicted in Fig. 
5. The data was collected using a Mitutoyo MVK-G1 micro-hardness tester with applied load of $100 \mathrm{gf}$. The reported hardness of each region is an average of 10 measurements.

\subsubsection{Solid liquid impingement testing}

The slurry erosion performance of the MMC coatings before and after FSP was evaluated using a closed loop solid liquid impingement test rig. A schematic diagram of the apparatus can be seen in Fig. 6. The benefits of a closed loop system include the ability to control the sand content of the slurry, vary the velocity of the flow and modify the stand-off distance of the impinging nozzle. These parameters have been shown in existing studies to influence the level of damage caused to the sample $[37,38]$.

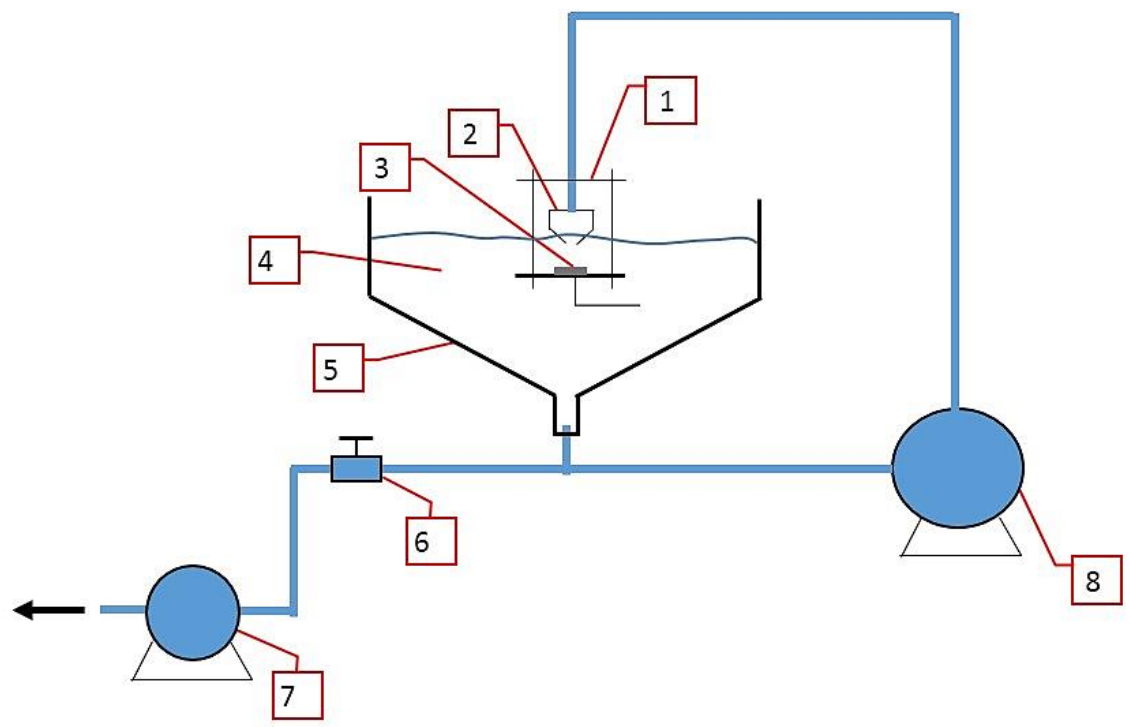

Fig 6. Schematic diagram of recirculating liquid impingement test rig (not to scale). (1) Sample holder; (2) Jet impingement nozzle; (3) Specimen; (4) Slurry solution; (5) Slurry tank; (6) Drainage valve; (7) Drainage pump; (8) Recirculating pump.

The $20 \mathrm{~mm}$ diameter test coupons were machined from the aluminium plate and positioned directly under the impinging nozzle. Prior to testing, all specimens were lightly abraded using 500 grit $\mathrm{SiC}$ paper to produce a uniform surface finish. The slurry used in the investigation consisted of $3.5 \% \mathrm{NaCl}$ and $\mathrm{FS} 9$ grade angular silica sand with an average particle size of $0.355 \mathrm{~mm}$. The test specimens were fully immersed in the slurry solution for the duration of the test. Following the conclusion of each test, the apparatus was flushed with fresh water to remove any trace particles, hence ensuring consistent testing conditions for each specimen. The experimental parameters are presented in Table 3.

Table 3. Solid liquid impingement test parameters. 


\begin{tabular}{llllll}
\hline $\begin{array}{l}\text { Flow Velocity } \\
(\mathrm{m} / \mathrm{s})\end{array}$ & $\begin{array}{l}\text { Sand Concentration } \\
(\mathrm{g} / \mathrm{l})\end{array}$ & $\begin{array}{l}\text { Stand-off } \\
\text { Distance }(\mathrm{mm})\end{array}$ & $\begin{array}{l}\text { Impingement } \\
\text { Angle }\left({ }^{(}\right)\end{array}$ & $\begin{array}{l}\text { Test Duration } \\
(\mathrm{min})\end{array}$ & $\begin{array}{l}\text { Sample } \\
\text { Diameter }(\mathrm{mm})\end{array}$ \\
\hline 22 & 0.4 & 20 & 90 & 20 & 20 \\
\hline
\end{tabular}

A mass balance (accuracy of $0.1 \mathrm{mg}$ ) was used to weigh the test coupons prior to and following erosion testing. Three test replicates were measured to establish the average mass loss. Volume loss was examined using an Alicona (Infinite Focus G4) non-contact optical surface characterisation system. The wear scar was divided into two distinct regions (impinged and turbulent) corresponding to the different flow characteristics over the specimen surface. The impinged zone is classified as the surface area directly beneath the $3 \mathrm{~mm}$ jet nozzle and relates to an area of $7.1 \mathrm{~mm}^{2}$. The volume loss from the entire wear scar and from the impinged zone was measured using the Alicona system. The difference between these two values represents the volume loss from the turbulent zone.

Analysis of the wear scar surface was carried out following slurry erosion testing to identify the underlying erosion mechanisms leading to the breakdown of the MMC coatings. The analysis was facilitated by high magnification micrographs of the wear scar captured using the SEM.

\section{Results and Discussion}

\subsection{MMC coating characterisation}

\subsubsection{Light optical microscopy}

Fig. 7 indicates the approx. location within the cold sprayed (Fig. 7a) and SprayStirred material (Fig. 7b) from which the micrographs in Fig. 8 were captured. Micrographs of the polished sections taken from the as-deposited and retreating side of the SprayStirred specimens are displayed in Fig. 8. Within the stir zone, the patterns of light and dark regions relate to the matrix and the reinforcing particles respectively.

A magnified cross section of the WC-CoCr coating is exhibited in Figure 8a. The absence of defects is attributed to the high velocities in cold spray and to the presence of the ductile metallic binder. Figure 8a also depicts agglomerates of WC-CoCr particles, resulting in areas within the coating that are void of any reinforcing particles. Quantitative image analysis of the micrographs revealed the coating to be comprised of approximately $56 \%$ (vol.\%) WC-CoCr and $44 \%$ binder. The measured value closely reflects the deposition ratio between the metallic binder and reinforcing particles (section 2.2). 


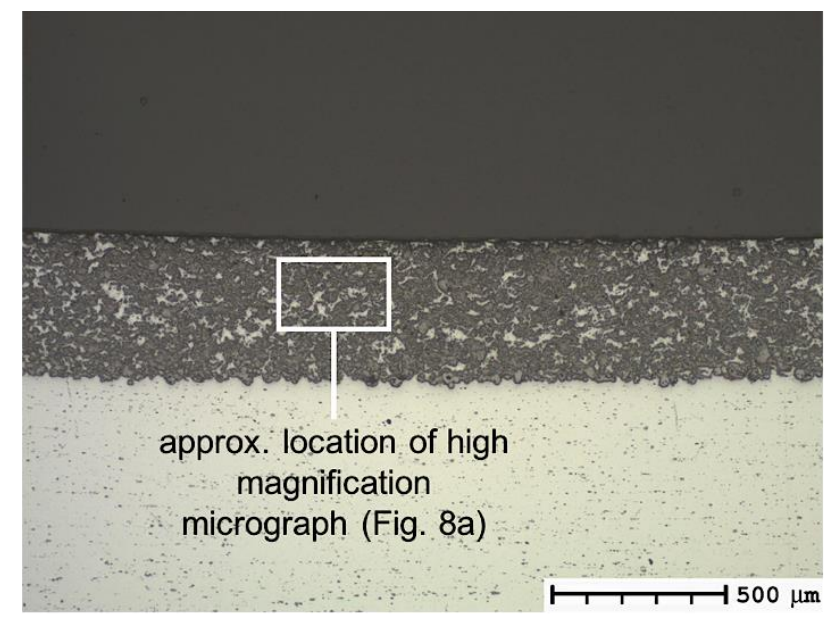

(a)

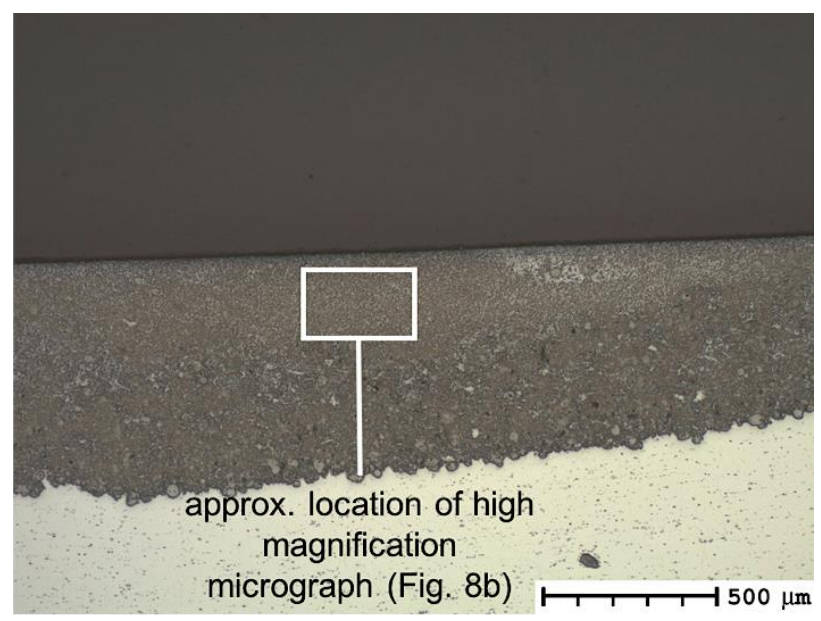

(b)

Fig. 7. Micrographs highlighting the approx. location of images shown in Fig. 8 [x50]. a) As-deposited cold spray coating; b) SprayStirred coating 


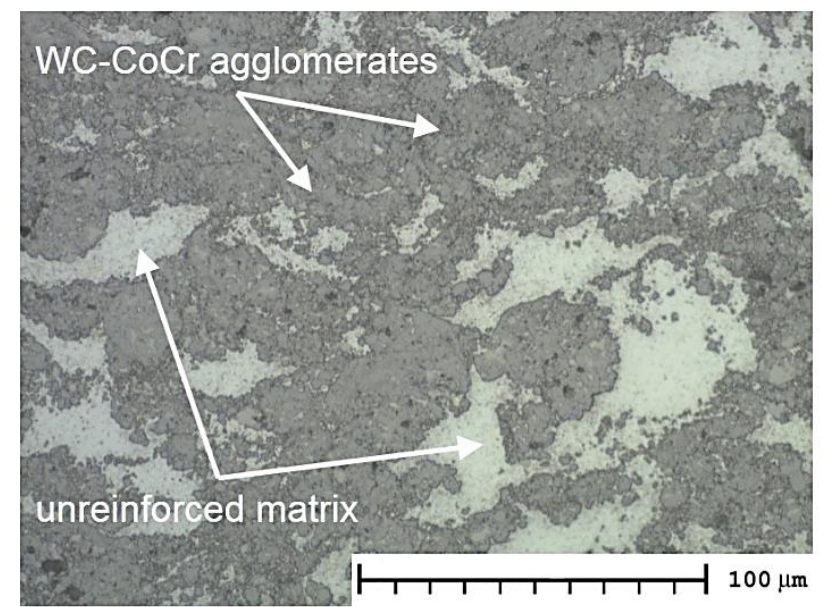

(a)

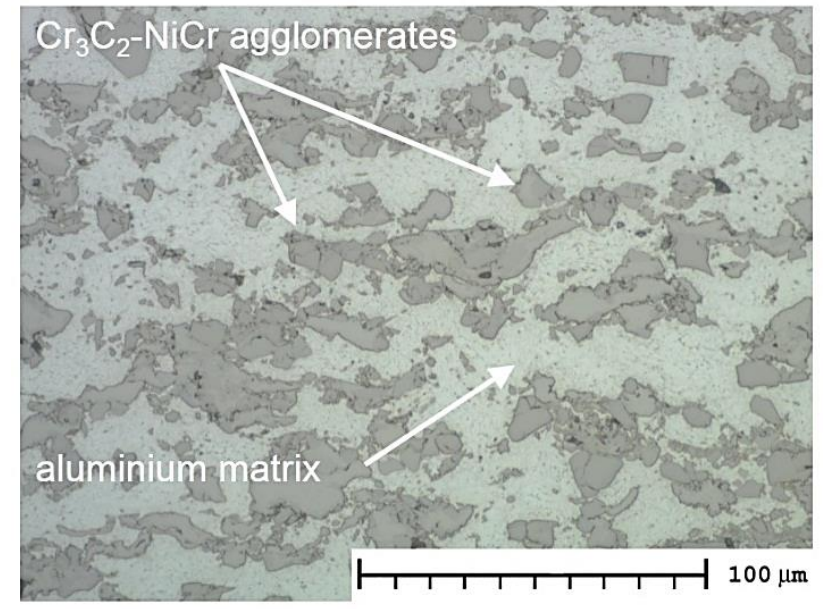

(c)

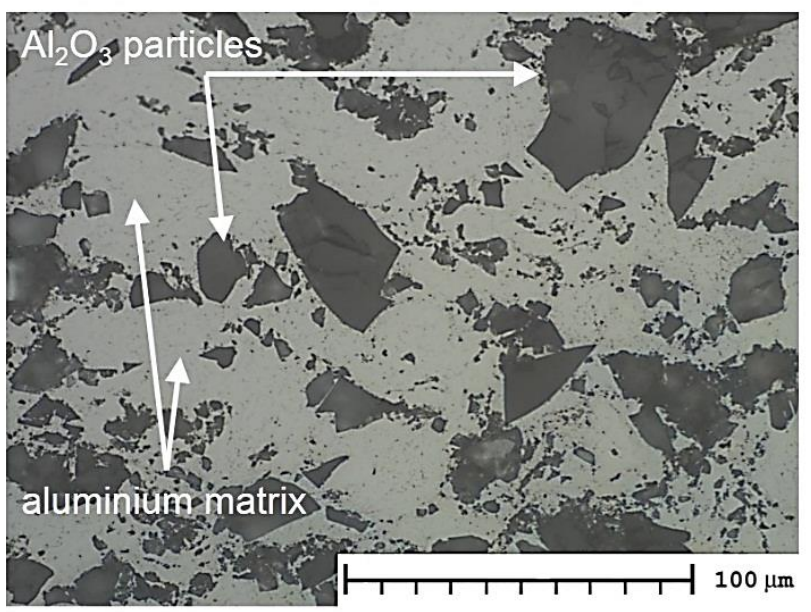

(e)

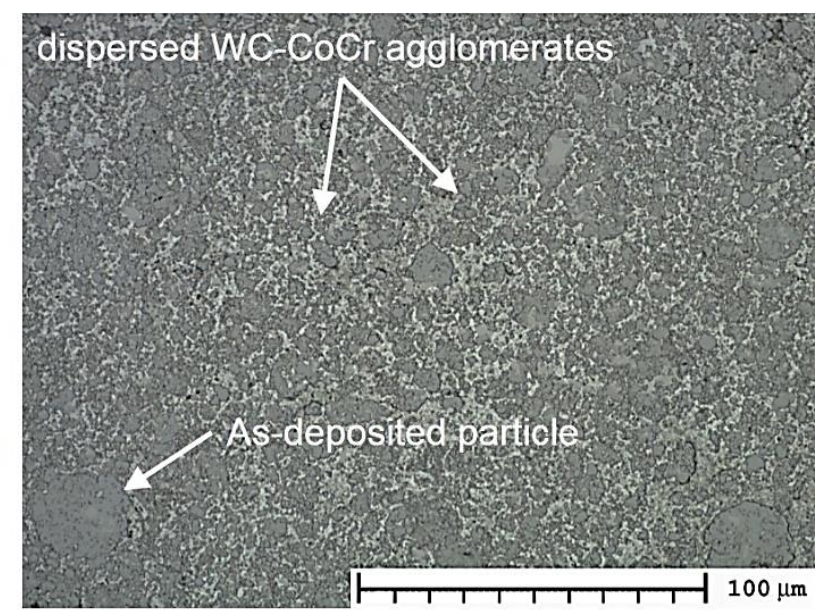

(b)

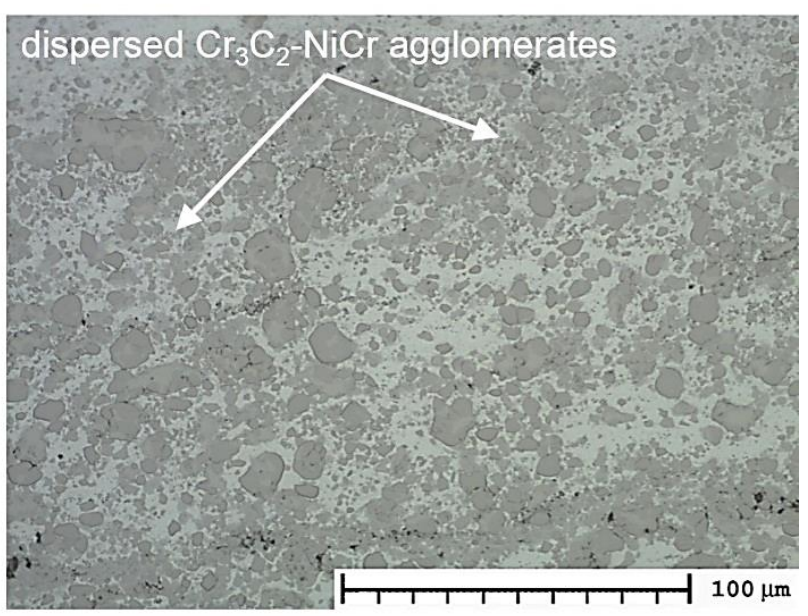

(d)

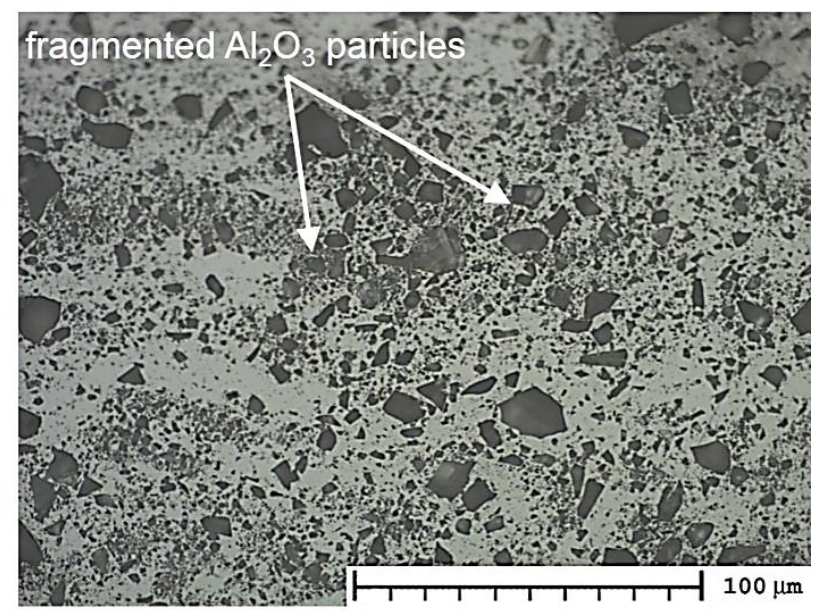

(f)

Fig. 8. Light optical micrographs of the MMC coatings [x500]. a) As-deposited WC-CoCr; b) as-deposited $\mathrm{Cr}_{3} \mathrm{C}_{2}-\mathrm{NiCr} ; \mathrm{c}$ ) as-deposited $\mathrm{Al}_{2} \mathrm{O}_{3}$; d) SprayStirred WC-CoCr; e) SprayStirred $\mathrm{Cr}_{3} \mathrm{C}_{2}-\mathrm{NiCr}$;) SprayStirred $\mathrm{Al}_{2} \mathrm{O}_{3}$ 
The micrographs in Fig. 8 present highly dissimilar microstructures before and after FSP. Fig. $8 \mathrm{a}$ and Fig. 8b illustrate the WC-CoCr reinforced MMC in the as-deposited and SprayStirred conditions respectively. Fig. 8b exhibits significant refinement of the WC-CoCr particles, with the agglomerates observed in the as-deposited condition dispersed by the FSP. This refinement is attributed to the shear forces that are exerted by the tool as it stirs the plasticised material $[39,40]$. During FSP, the agglomerates are deformed beyond the elastic limit of their respective binder alloys resulting in the dispersal of the individual carbides throughout the matrix. However, some particles can be observed at sizes of approx. $20 \mu \mathrm{m}$, thereby showing that not all of the as-deposited powder has been broken down by the FSP. In existing studies $[41,42]$, the level of refinement has been shown to increase with the number of FSP passes. Therefore, it is expected that additional FSP passes through the MMC would distribute any traces of the as-deposited reinforcing particles to a greater extent.

The same mechanism is present in both the $\mathrm{Cr}_{3} \mathrm{C}_{2}-\mathrm{NiCr}$ (Fig. 8d) and $\mathrm{Al}_{2} \mathrm{O}_{3}$ (Fig. 8f) reinforced MMCs which also demonstrate substantial particle refinement after FSP. The large $\mathrm{Al}_{2} \mathrm{O}_{3}$ particles observed in Fig. $8 \mathrm{c}$ have been broken down and dispersed throughout the matrix by the rotating motion of the FSP tool. This has resulted in a more homogenous distribution of reinforcements when compared to the as-deposited coating (Fig. 8c). Fig. 8e reveals increased particle refinement along the top of the image corresponding to the region that is exposed to the greatest temperatures and forces from the tool shoulder [13]. The effects are also apparent in WC-CoCr and $\mathrm{Al}_{2} \mathrm{O}_{3}$ coatings with both depicting a greater level of refinement towards the top surface. This feature is highlighted in Fig. 9.

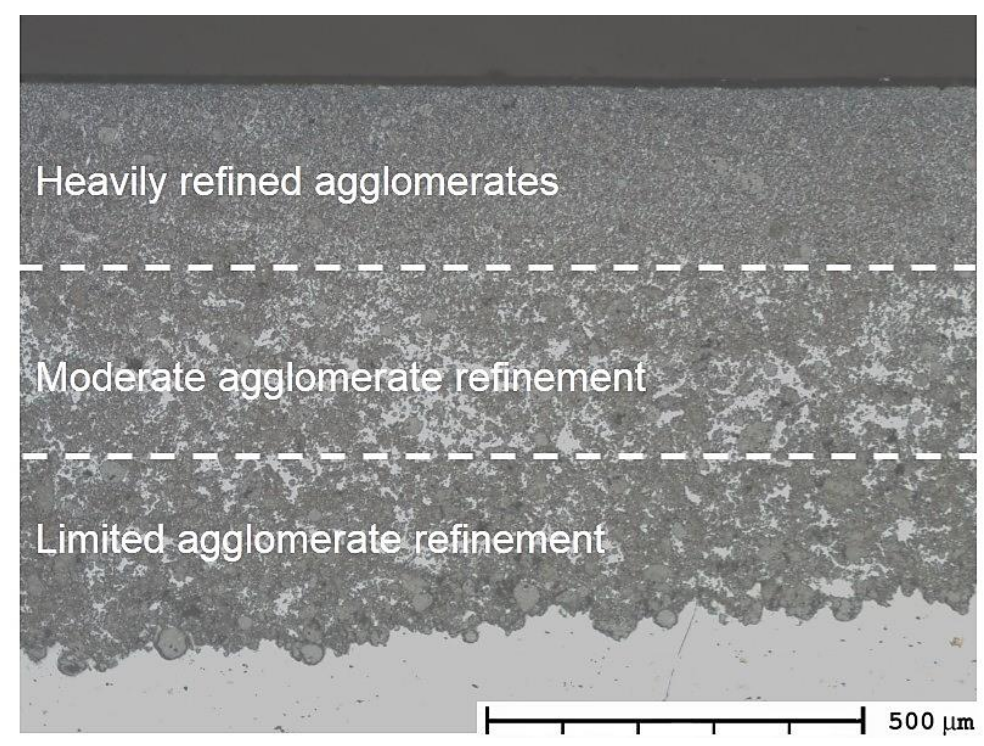

Fig 9. Variation in particle refinement through the depth of the SprayStirred MMC. 


\subsubsection{Scanning electron microscopy}

The particle distribution before and after FSP is exhibited in the EDS image maps depicted in Fig. 10.
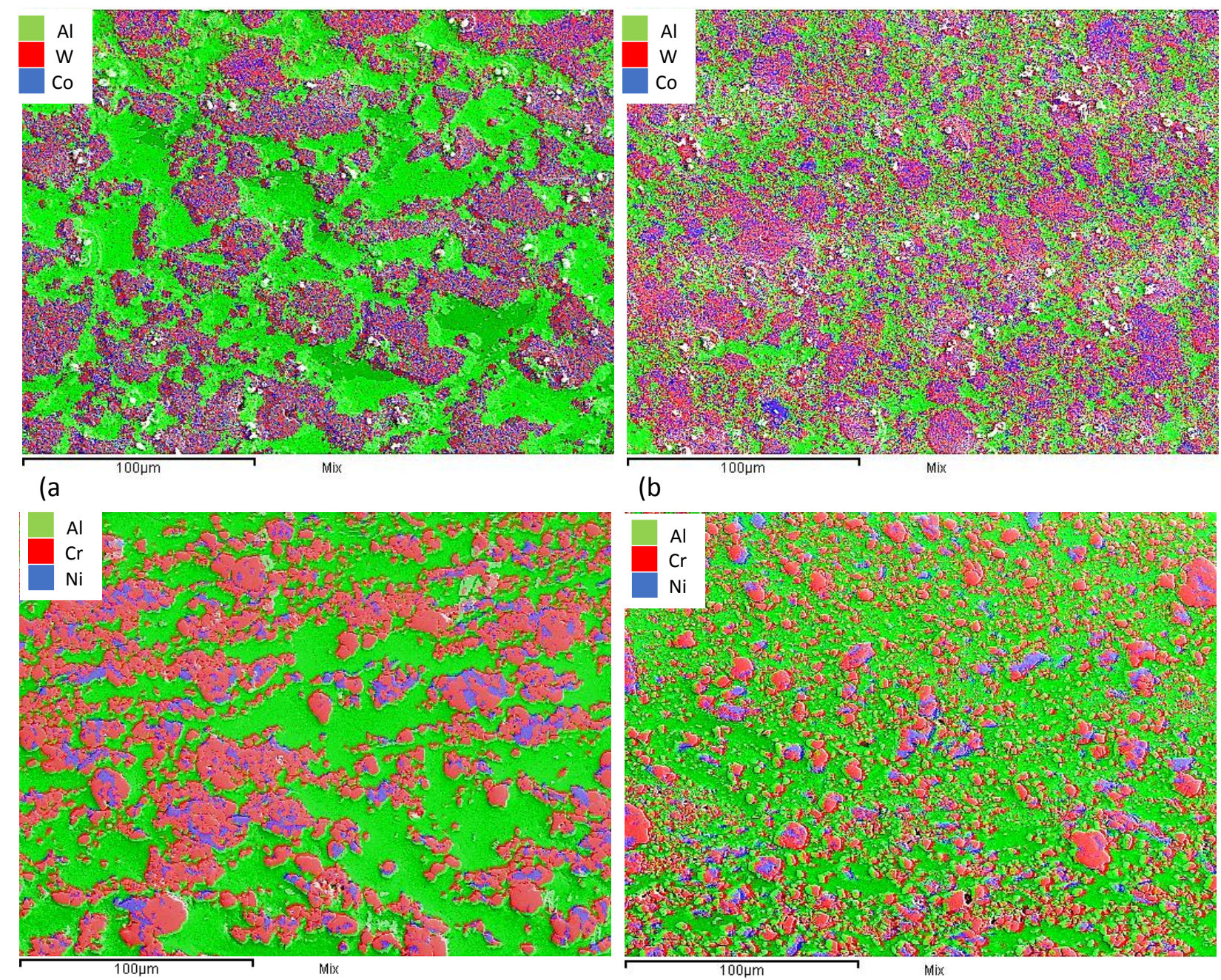

(b

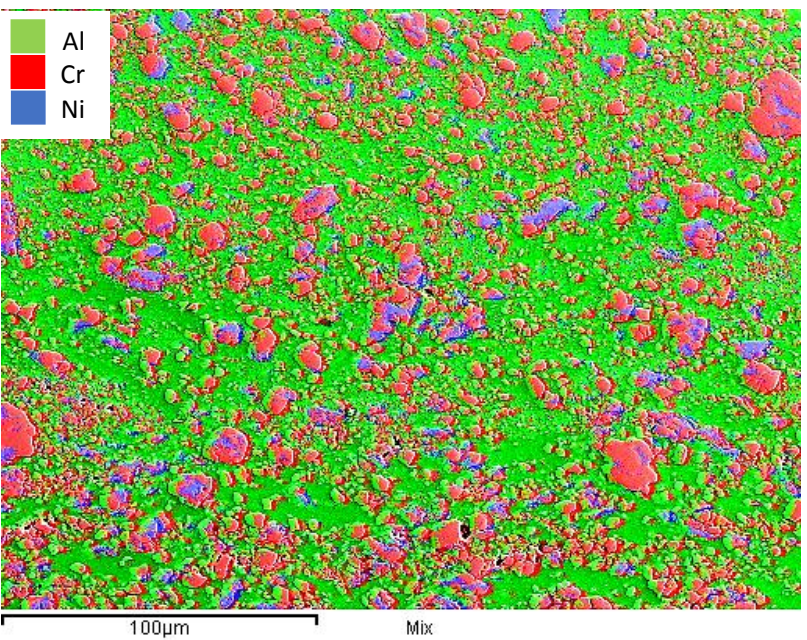

(c

$(d$

Fig 10. EDS mapping showing distribution of reinforcing particles [x500]. a) As-deposited WC-CoCr, b) SprayStirred WC-CoCr, c) As-deposited $\mathrm{Cr}_{3} \mathrm{C}_{2}-\mathrm{NiCr}$, d) SprayStirred $\mathrm{Cr}_{3} \mathrm{C}_{2}-\mathrm{NiCr}$.

Fiedler et al. [43] noted that micro-reinforcement mechanisms occur as a result of improved dispersion and reduced agglomerations. As demonstrated in Fig. 10, this has been accomplished through the use of FSP on the co-deposited MMCs. The wt.\% of the various elements within the MMC coating was also analysed using EDS software and is displayed in Table 4. The results highlight a significant quantity of reinforcement material in the as-deposited coating and therefore validates the findings from the optical microscopy. The values contained in Table 4 also reveal a drop in the quantity of reinforcement on the advancing side of the stir 
zone. This is accompanied by a corresponding rise in the quantity of reinforcement on the retreating side of the stir zone. This outcome is attributed to the tool design used in the study and specifically to the threaded probe of the tool.

Table 4. EDS elemental analysis (wt.\%)

\begin{tabular}{lllllllll}
\hline & & $\mathrm{Mg}$ & $\mathrm{Al}$ & $\mathrm{Cr}$ & $\mathrm{Ni}$ & $\mathrm{Co}$ & $\mathrm{W}$ & $\mathrm{O}$ \\
\hline \multirow{2}{*}{ As-Deposited } & $\mathrm{WC}-\mathrm{CoCr}$ & 1.51 & 32.22 & 2.54 & & 5.54 & 58.19 & \\
& $\mathrm{Cr}_{3} \mathrm{C}_{2}-\mathrm{NiCr}$ & 2.06 & 39.52 & 42.92 & 15.51 & & & \\
& $\mathrm{Al}_{2} \mathrm{O}_{3}$ & 2.60 & 86.06 & & & & & 11.35 \\
\hline SprayStirred & $\mathrm{WC}-\mathrm{CoCr}$ & 0.83 & 19.35 & 3.29 & & 7.68 & 68.85 & \\
(Retreating) & $\mathrm{Cr}_{3} \mathrm{C}_{2}-\mathrm{NiCr}$ & 2.09 & 39.82 & 41.85 & 16.23 & & & \\
& $\mathrm{Al}_{2} \mathrm{O}_{3}$ & 2.56 & 86.48 & & & & & 10.96 \\
\hline SprayStirred & $\mathrm{WC} \mathrm{CoCr}$ & 1.54 & 33.79 & 2.78 & & 5.95 & 55.95 & \\
(Advancing) & $\mathrm{Cr}_{3} \mathrm{C}_{2}-\mathrm{NiCr}$ & 2.23 & 49.51 & 36.34 & 11.92 & & & \\
& $\mathrm{Al}_{2} \mathrm{O}_{3}$ & 2.84 & 90.4 & & & & & 6.67 \\
\hline
\end{tabular}

\subsubsection{Micro-hardness}

The micro-hardness distribution across the width of the stir zone and the average microhardness of the substrate (pre- and post-FSP) is presented in Fig. 11.

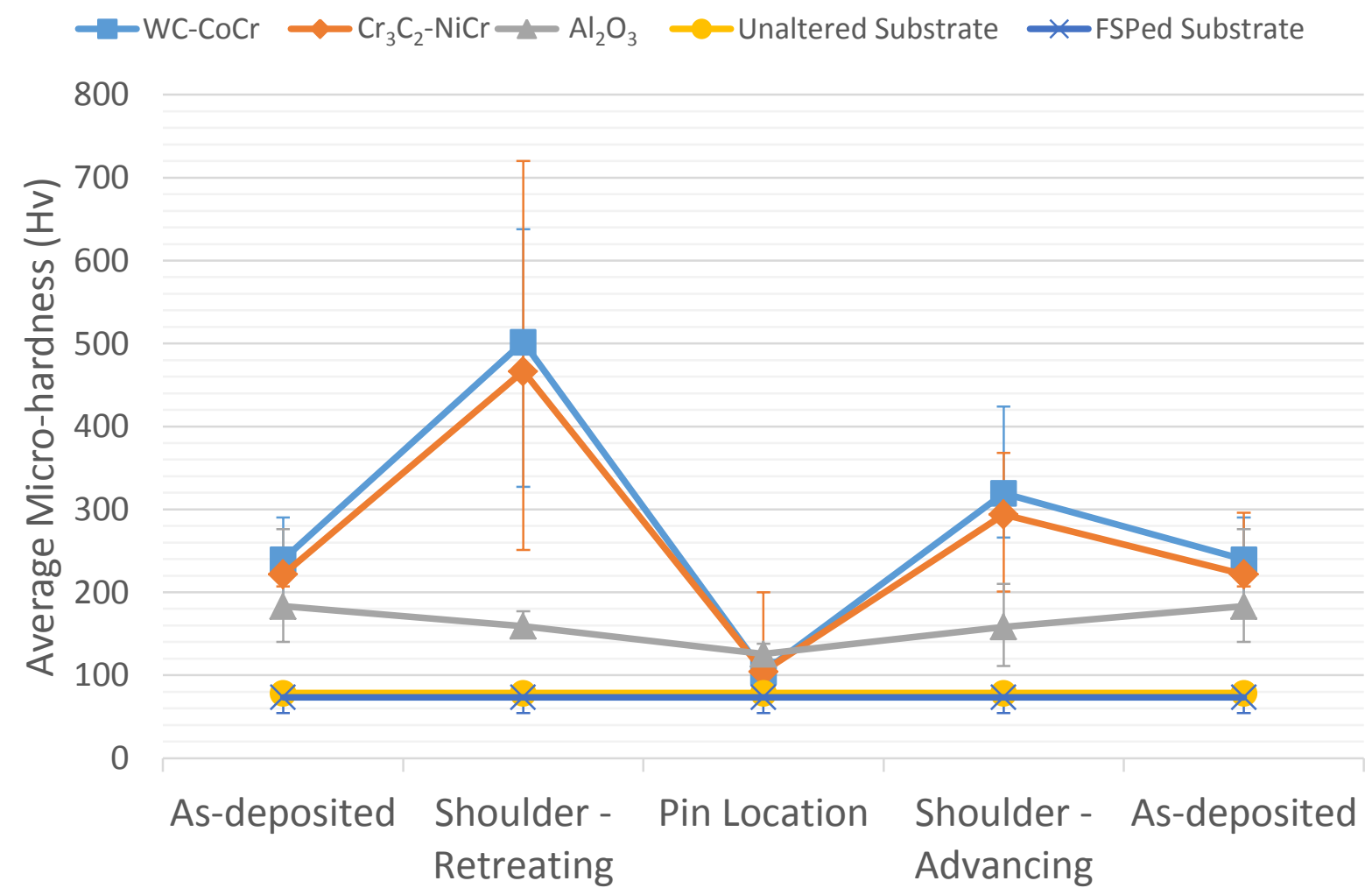


The broad scatter of results in Fig. 11 occurs as a result of indentations made on either a hard carbide particle or on the softer ductile matrix. The results show that FSP has little effect on the average hardness of the substrate (no reinforcing particles). This is an unexpected outcome considering that a number of authors state that an increase in micro-hardness is one of the primary benefits of FSP $[44,45]$. The lack of any hardness increase identified in the present study has also been reported by Chen et al. [46] whilst investigating the effect of FSP on the mechanical properties of AA5083.

Analysis of the SprayStirred specimens reveals a noticeable drop in the micro-hardness towards the centre of the stir zone. Optical micrographs of the hardness indents can be seen in Fig. 12 and show the proximity and quantity of reinforcing particles in each region within the stir zone. Analysis of the region that the pin traverses through highlights a lack of reinforcing particles. The minimal presence of reinforcements in this region is attributed to the pin forcing particles from the surface towards the base of the stir zone; this phenomenon can be seen in Fig. 13.
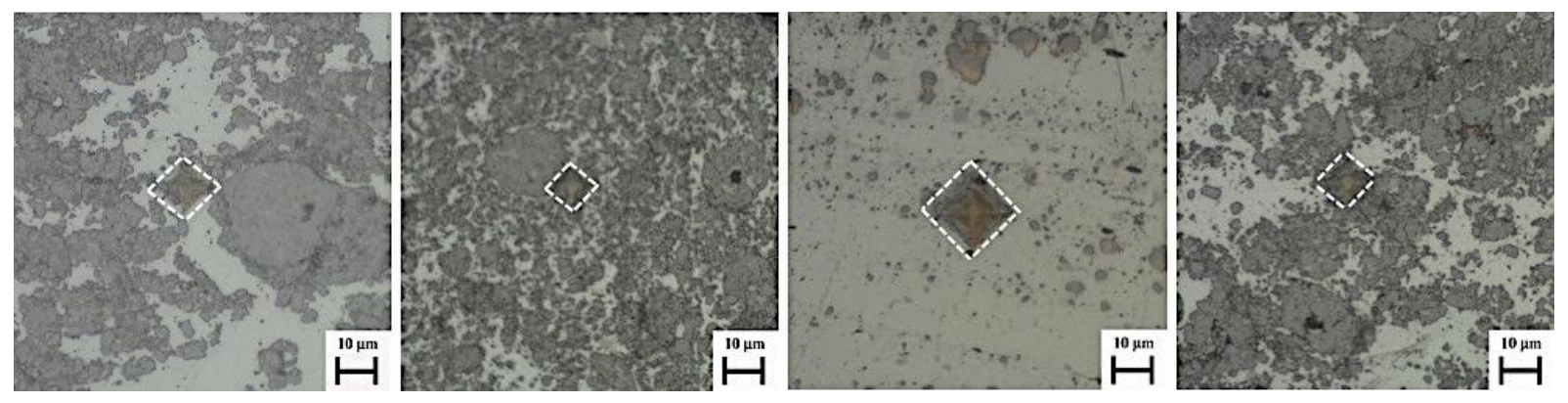

Fig. 12 Hardness indents showing the level of surrounding WC-CoCr particles [x500]. a) As-deposited; b) Retreating side; c) Pin location; d) advancing side.

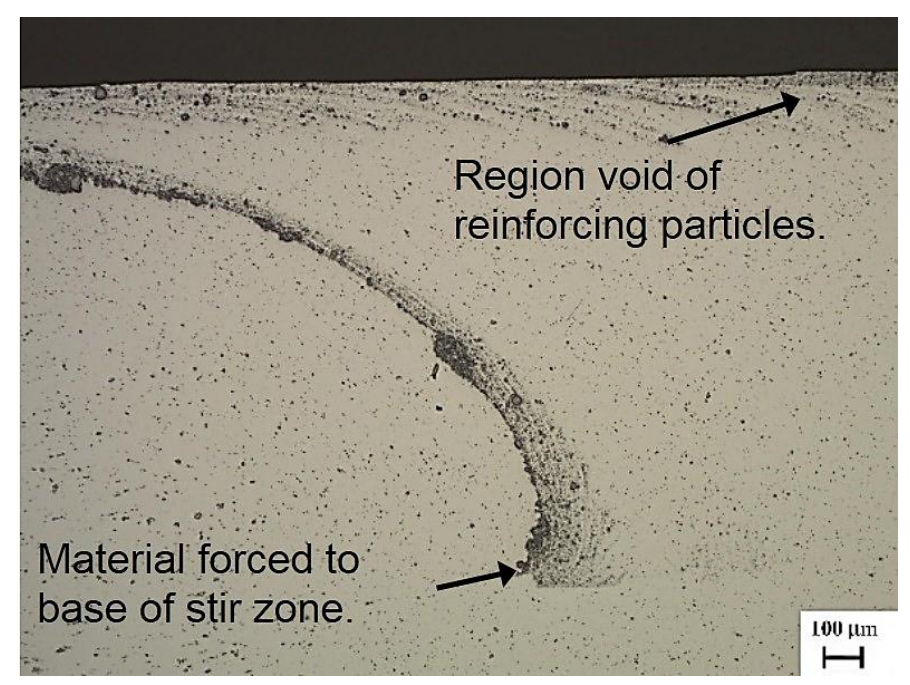


Fig 13. Light optical micrograph showing reinforcing particles being pulled down from the surface [x50].

The greatest hardness values were measured on the retreating side of the stir zone. On this side, the WC-CoCr and $\mathrm{Cr}_{3} \mathrm{C}_{2}-\mathrm{NiCr}$ reinforced coatings exhibited an average hardness increase of approx. 540\% and 495\% respectively over the as-received substrate. The addition of $\mathrm{Al}_{2} \mathrm{O}_{3}$ particles has resulted in a comparatively lower hardness increase to the MMC of $103 \%$. This is attributed to a lower quantity of reinforcing particles in the MMC and the increased distance between neighbouring particles (see section 3.1.4). The superior hardness found on the retreating side of the stir zone corresponds to a reduction in the interparticle spacing of the WC-CoCr material after FSP (Table 4). These results demonstrate the impact of tool design on the distribution of reinforcing particles. The tool design in the current study has resulted in greater quantities of reinforcing particles being transported to the retreating side as opposed to being evenly distributed across the top surface of the coating layer. This outcome aligns with the results of the EDS analysis.

\subsubsection{Interparticle spacing}

There have been a number of studies [22,25] that relate the hardness of an MMC to the distribution of reinforcements, specifically to the spacing between particles (interparticle spacing) within the MMC. Whilst not directly measuring hardness, Kouzeli et al. [47] developed a method to quantify this by superimposing a number of lines with known length on a micrograph of the MMC. The number of particle intercepts with the lines and the volume fraction of reinforcing particles was used to calculate the average interparticle distance [47]. Despite providing a good indication of the spacing between adjacent particles, this method fails to account for particle agglomeration and dispersal quality. As such, this method does not allow direct comparisons to be made between MMCs containing evenly dispersed and agglomerated reinforcing particles.

To address this, several authors [48-50] have investigated the generation of statistical models that are capable of quantifying the level of dispersion in MMCs. Khare \& Burris [48] developed a method that measures the free-space length which is defined as the width of the largest randomly placed square for which the average number of intersecting particles is zero. The presence of particle agglomerates is accounted for by measuring the largest free-space length. Hence, Khare and Burris' method [48] was applied to highlight the variation in interparticle spacing between the as-deposited and SprayStirred MMCs. The results are offered in Table 5.

Table 5. Interparticle distance 


\begin{tabular}{llll}
\hline Coating & WC-CoCr & $\mathrm{Cr}_{3} \mathrm{C}_{2}-\mathrm{NiCr}$ & $\mathrm{Al}_{2} \mathrm{O}_{3}$ \\
\hline $\begin{array}{l}\text { Interparticle distance }(\mu \mathrm{m}) \\
\text { (as-deposited) }\end{array}$ & 11.5 & 15.3 & 13.1 \\
\hline $\begin{array}{l}\text { Interparticle distance }(\mu \mathrm{m}) \\
\text { (SprayStirred) }\end{array}$ & 3.7 & 5.8 & 8.6 \\
\hline $\begin{array}{l}\text { Reduction in interparticle } \\
\text { distance (\%) }\end{array}$ & 68 & 60 & 34 \\
\hline
\end{tabular}

The results indicate a $68 \%$ and $75 \%$ decrease in the average interparticle spacing in the WC-CoCr and $\mathrm{Cr}_{3} \mathrm{C}_{2}$-NiCr coatings following FSP. SprayStirred $\mathrm{Al}_{2} \mathrm{O}_{3}$ resulted in a smaller decline in interparticle distance of $34 \%$. The decrease in the level of refinement experienced by the $\mathrm{Al}_{2} \mathrm{O}_{3}$ particles, as compared with the tungsten and chromium based reinforcements, is primarily attributed to the morphology of the oxide particles. The $\mathrm{Al}_{2} \mathrm{O}_{3}$ powder is comprised of solid particles without ductile binder whereas the cermet powders are agglomerates of smaller carbides retained by a binding alloy that can be refined to a greater extent by the stirring motion of the FSP tool. Despite the variation in the level of reduction experienced by each coating, the results highlight the beneficial effects of FSP by showing a reduction in the interparticle spacing for all SprayStirred coatings.

\subsection{Solid liquid impingement erosion study}

\subsubsection{Mass loss}

Fig. 14 displays the influence of FSP on the mass loss experienced by the three particle reinforced MMCs and the as-received AA5083 substrate material. The results demonstrate a reduction in the mass loss of the MMC coatings after FSP. However, the erosion performance of the uncoated substrate exhibits no measurable decline in the mass loss experienced following FSP. This outcome highlights a correlation between the recorded micro-hardness values which also revealed no change between the pre- and post-FSP conditions. The link between hardness and erosion performance has been reported in prior publications, all of which examined the erosion performance of thermal spray coatings when exposed to a slurry test environment $[51,52]$. The WC-CoCr reinforced MMC has shown a reduction in mass loss of approx. $75 \%$. This drop constitutes the greatest improvement in erosion performance following FSP out of all the examined coatings and is attributed to the dispersal of the large WC-CoCr agglomerates and a subsequent reduction in the interparticle spacing.

Due to the highly dissimilar densities (Table 1) of the three types of powder particles, the mass loss data cannot be used to carry out a comparative analysis between the three coatings' erosion performance. To enable a comparative analysis of the three coatings, the volume loss 
within the wear scar was measured using an Alicona non-contact surface characterisation system.

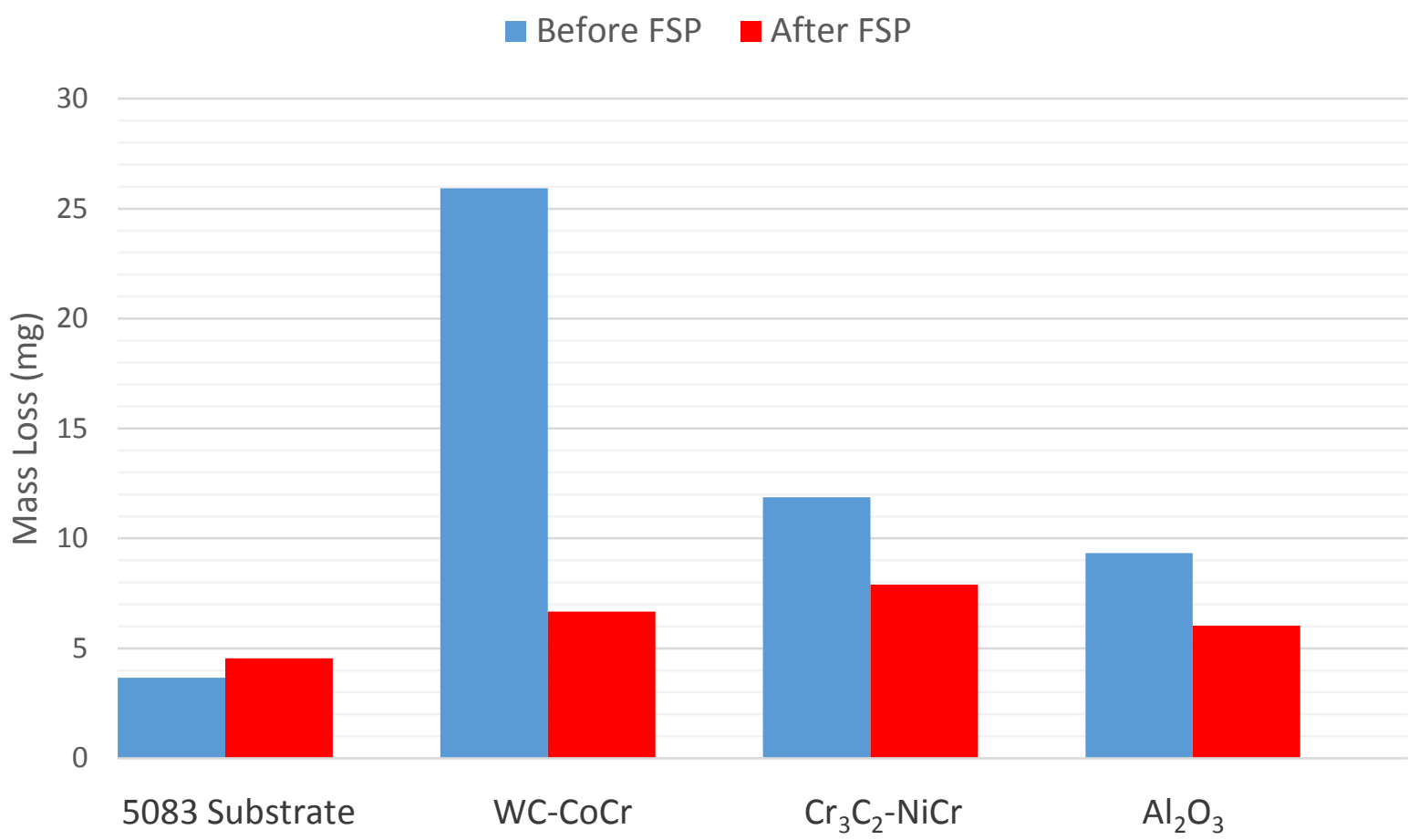

Fig. 14. Mass loss of the MMC coatings pre- and post-FSP.

\subsubsection{Volume loss}

The volume loss in the direct and turbulent regions of the wear scar was measured independently to investigate the contribution of each region to the total volume loss. The corresponding data can be seen in Fig. 15. The $\mathrm{Al}_{2} \mathrm{O}_{3}$ reinforced $\mathrm{MMC}$ has experienced the greatest improvement in erosion performance post-FSP, recording a $36 \%$ decrease in the total volume loss. The direct and turbulent zones exhibited a drop in volume loss of $33 \%$ and $43 \%$ respectively. The significant improvement in erosion performance is attributed to the level of refinement of the oxide particles and associated drop in the interparticle spacing (Table 5).

In the pre- and post-FSP conditions, the uncoated AA5083 material has resulted in similar levels of volume loss. This is an unexpected outcome considering that a number of authors $[53,54]$ report an improvement to the erosion performance of the alloy post-FSP. However, the volumetric results do align with the outcome of the micro-hardness analysis, which also demonstrated no change in hardness before and after FSP [51,52]. The volume loss measured in the turbulent zone is less than the direct zone in all of the examined MMC coatings. Contrarily, the primary contributor to the volume loss experienced by the uncoated specimen is material loss from the turbulent region. This outcome is related to the greater 
hardness of the MMCs which resist the sand particles scoring across the surface. The variation in wear mechanisms will be expanded on in section 3.2.3.

Prior to FSP, the WC-CoCr and $\mathrm{Al}_{2} \mathrm{O}_{3}$-based MMCs have resulted in similar levels of volume loss. This corresponds to the large $\mathrm{Al}_{2} \mathrm{O}_{3}$ oxides behaving similarly to the $\mathrm{WC}-\mathrm{CoCr}$ agglomerates (which act as large particles). Post-FSP, the volume loss experienced by the $\mathrm{Al}_{2} \mathrm{O}_{3}$ coatings is reduced, however, the drop in volume loss experienced by the WC-CoCr is even higher. Whilst the $\mathrm{Al}_{2} \mathrm{O}_{3}$ particles are substantially refined post-FSP, the particles are still larger than the carbides in the WC-CoCr MMC (Table 1). Consequently, the greater erosion performance of the SprayStirred WC-CoCr MMC aligns with the presence of fine reinforcements and reduced interparticle spacing.

The SprayStirred $\mathrm{Al}_{2} \mathrm{O}_{3} \mathrm{MMC}$ has experienced lower volume loss than the $\mathrm{Cr}_{3} \mathrm{C}_{2}-\mathrm{NiCr}$ coating despite the greater interparticle distance between reinforcements. Thus, the interparticle spacing is not the only parameter that governs the erosion performance of the MMC. The hardness and toughness of the reinforcing particles must be sufficient to oppose the impacting silicon carbide particles without cracking. The significant refinement of the oxide particles by the FSP has increased the number of particles that are less than $1 \mu \mathrm{m}$ and as such, the $\mathrm{Al}_{2} \mathrm{O}_{3}$ reinforced MMC benefits from increased dispersion strengthening [20], resulting in lower volume loss.

Direct Zone $\quad$ Turbulent Zone

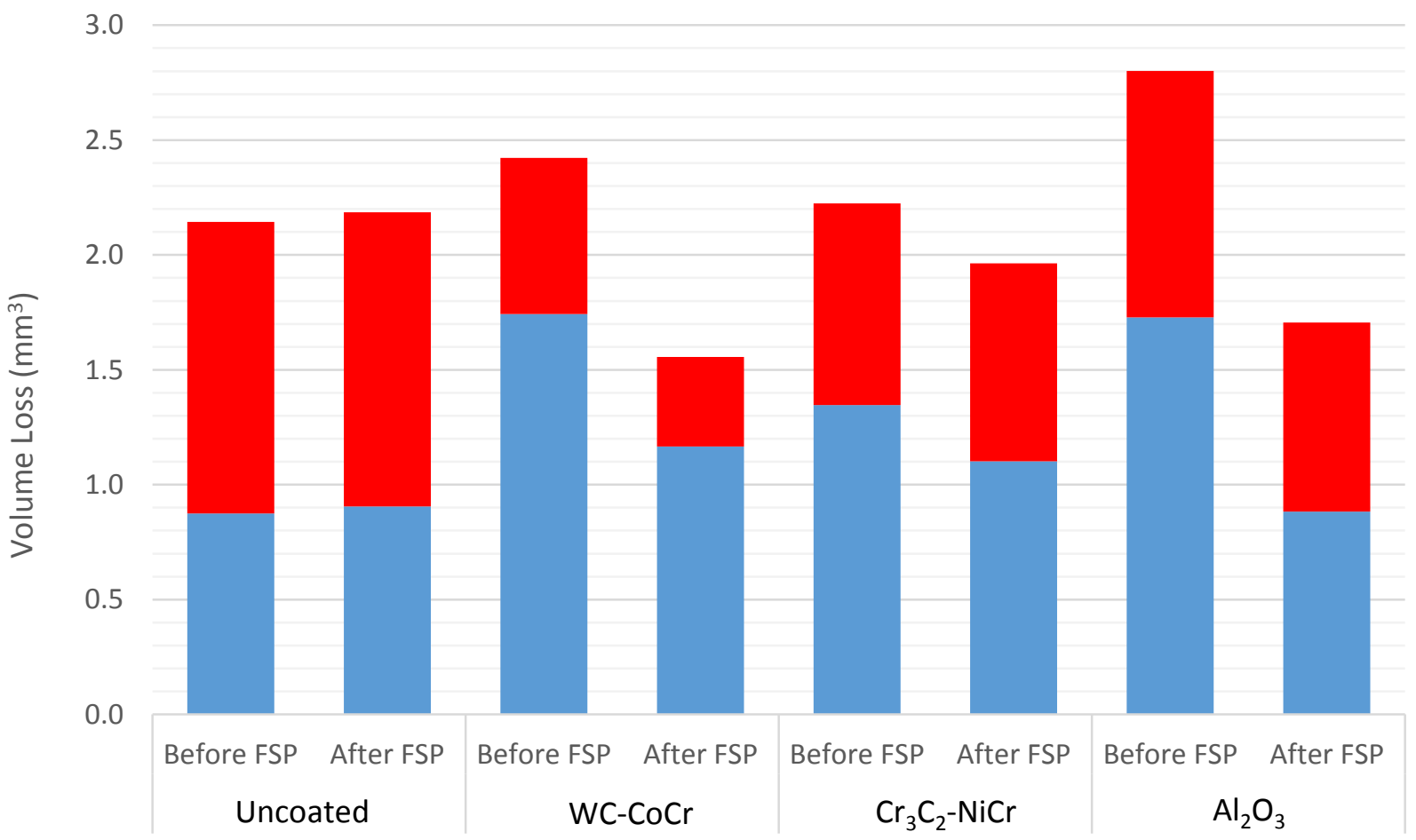


Fig. 15. Volume loss in the direct and turbulent regions of the wear scar.

\subsubsection{Wear scar analysis}

As discussed in section 3.2.2, the erosion mechanisms that act upon the surface of the specimens differ depending on the properties of the particular coating. SEM micrographs of the impinged regions (Fig. 16) were examined to identify the specific mechanisms acting on the MMC coatings and the uncoated AA5083 material.

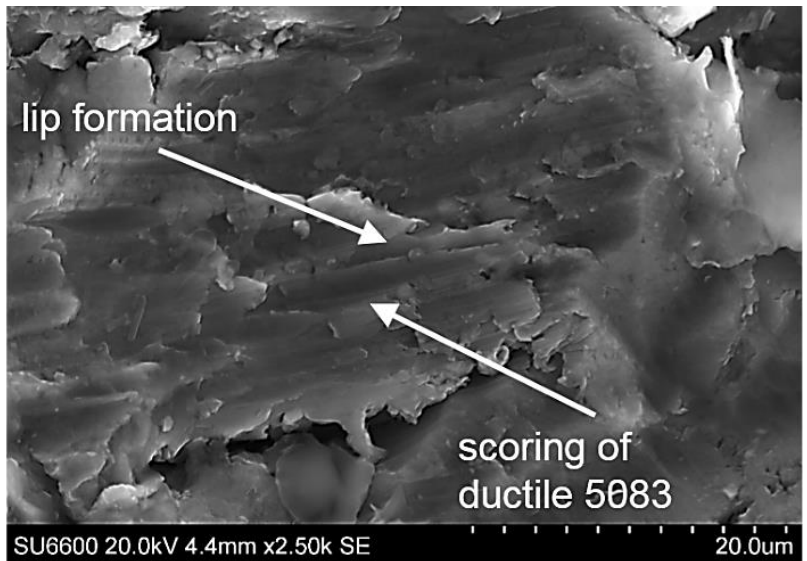

(a)

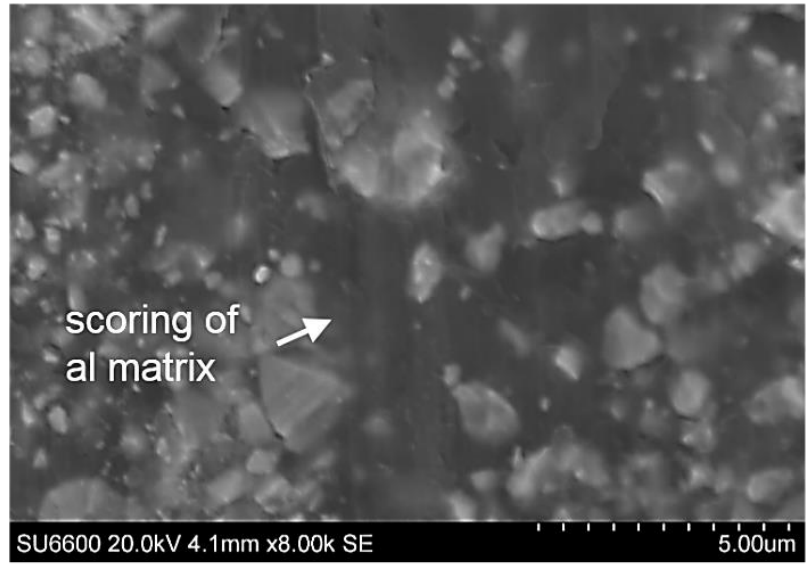

(c)

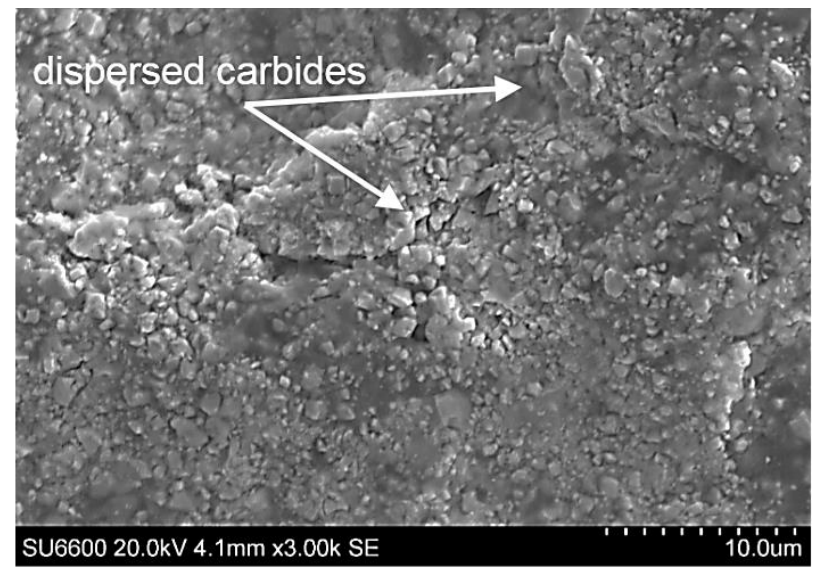

(b)

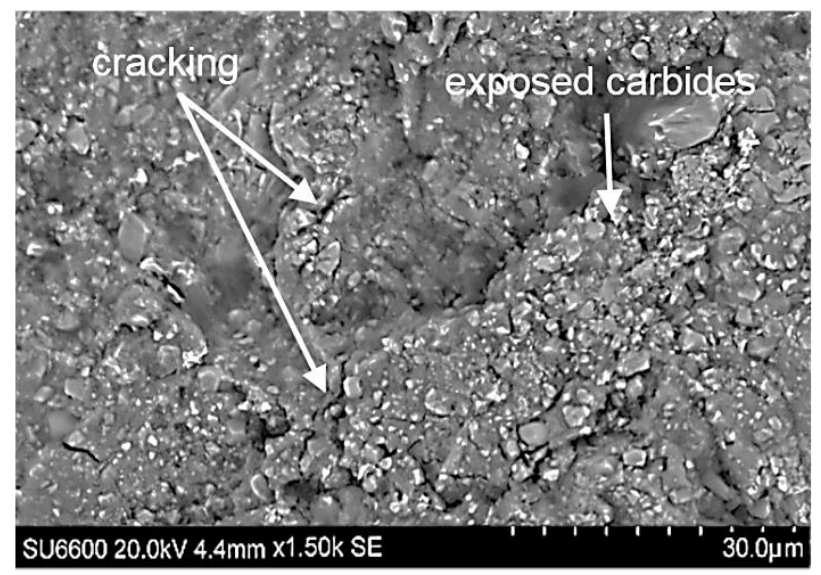

(d)

Fig. 16. Scanning electron micrographs of the wear scar. a) Uncoated [x2500]; b) WC-CoCr [x3000]; c) WC-CoCr [x8000]; d) $\mathrm{Cr}_{3} \mathrm{C}_{2}-\mathrm{NiCr}[\times 1500]$

Fig. 16a exhibits substantial scoring and lip formation within the impinged zone on the uncoated AA5083 substrate. Directionality and parallel scratch patterns are also evident from the image (Fig. 16a). This scar pattern is consistent with the erosion of ductile materials as noted by Finnie [55]. The primary mechanisms causing material loss, as identified by previous research [56,57], can be attributed to cutting and scoring of the ductile matrix. Repeated impact 
leads to the formation of lips (Fig. 16a). Continued exposure to the high velocity jet causes the removal of these lips resulting in an associated volume loss.

The impinged region of the WC-CoCr reinforced SprayStirred coating is presented in Fig. 16b and reveals a significant quantity of tungsten carbides exposed to the impinging slurry. To generate this feature on the surface of the specimen, the slurry has removed the soft, ductile matrix that surrounds the carbides. Without this retaining matrix, continued exposure to the impinging jet causes the carbides to be pulled from the surface. Furthermore, an electron micrograph depicting a region of matrix alloy within the SprayStirred MMC (Fig. 16c) exhibits signs of ploughing that are consistent with ductile material removal. This feature is commonly referred to in the published literature and is reported as the primary erosion mechanism for particle reinforced alloys $[26,52,58,59]$. However, the exposure of carbides does highlight their uniform distribution in the MMC. In this case, the quantity of material removed is decreased as a result of less ductile matrix exposed to the impinging slurry.

Evidence of the same mechanism was found in the $\mathrm{Cr}_{3} \mathrm{C}_{2}-\mathrm{NiCr}$ coating, as demonstrated by the exposed carbides shown in Fig. 16d. The level of damage experienced by this coating is attributed to the greater interparticle spacing and the lower hardness of the chromium carbides (as compared with WC-CoCr). The increased distance between neighbouring particles has led to a greater surface area of matrix being exposed to the impinging slurry, while the hardness of the chromium carbides is not sufficient to resist the impacting silicon carbides which have caused cracking in the wear scar (Fig. 16d).

\section{Conclusions}

WC-CoCr, $\mathrm{Cr}_{3} \mathrm{C}_{2}-\mathrm{NiCr}$ and $\mathrm{Al}_{2} \mathrm{O}_{3}$ powders have successfully been co-deposited with a metallic binder to produce particle reinforced MMC coatings. These coatings have subsequently been subjected to FSP, the aim of which was to improve the distribution of reinforcing particles within the MMC matrix. Coatings in the as-deposited and SprayStirred conditions were examined under solid liquid impingement test conditions. The mass and volume loss of each specimen was measured to quantify any change to the erosion performance of the MMC postFSP. The following conclusions can be drawn from this body of work.

- The shear forces generated by the FSP tool have resulted in substantial refinement of the reinforcing particles. Micrographs revealed that the particles have been evenly dispersed throughout the MMC matrix. Moreover, the WC-CoCr agglomerates present in the as-deposited condition have been dispersed by the FSP. 
- The reduction in interparticle spacing post-FSP has been quantified for each reinforcing particle using a statistical analysis approach. Results revealed that FSP has been successful in reducing the average interparticle distance of all three coatings, with the WC-CoCr reinforced MMC exhibiting a reduction of $65 \%$.

- In the case of the WC-CoCr reinforced MMC, FSP has resulted in approx. $120 \%$ increase in the average hardness over the as-deposited MMC. This increase is attributed to the particle refinement and reduction in the interparticle distance of the reinforcements.

- The tool geometry employed in this study has led to a build-up of reinforcing particles on the retreating side of the stir zone. This has prevented an even distribution of reinforcing particles across the top surface of the substrate. As a consequence of the $2 \mathrm{~mm}$ pin, the reinforcing particles have been pushed towards the base of the stir zone thus resulting in a region that is void of any reinforcing particles in the centre of the processed zone. Hence, the centre of the stir zone demonstrates only minor hardness increase over the as-received substrate.

- The hardness of the MMC coatings is highly dependent on the quantity of reinforcing particles in the surrounding matrix which limits the deformation of the ductile matrix alloy. The measured hardness values correlate with the interparticle distance, with coatings recording the highest hardness (WC-CoCr) also presenting the smallest interparticle distance.

- Volumetric analysis of as-deposited and SprayStirred coatings following solid liquid impingement testing has highlighted the improved performance of the SprayStirred MMC coatings under slurry erosion conditions. The findings of this study attribute the poor performance of the as-deposited MMC coatings to agglomeration of reinforcing particles within the matrix. The FSP process has been shown to effectively break-up and disperse the agglomerates resulting in a homogenous distribution of particle reinforcements.

- $\mathrm{Al}_{2} \mathrm{O}_{3}$ exhibited the greatest improvement in erosion performance following FSP with the volume loss decreasing by approx. 40\%. Despite this, WC-CoCr recorded the lowest volume loss out of all the examined coatings. The superior erosion properties of this $M M C$ are attributed to the uniform distribution of fine reinforcing particles.

- The primary wear mechanisms operating within the MMC coatings have been evaluated through examination of the impinged regions. The findings highlight damage to the softer matrix alloy in the form of ploughing which subsequently exposes carbide/oxide particles to the impinging slurry. The SprayStirred surfaces presented a reduction in the 
interparticle spacing, hence less of the matrix alloy was exposed to the impinging slurry. Consequently, the volume loss is lower in the SprayStirred specimens when compared with the corresponding as-deposited coatings.

\section{References}

[1] A. Papyrin, V. Kosarev, S. Klinkov, A. Alkhimov, V. Fomin, Cold Spray Technology, Elsevier, 2006.

[2] V.K. Champagne, The cold spray materials deposition process: fundamentals and applications, Woodhead Publishing, 2007.

[3] L. Singh, V. Chawla, J.S. Grewal, A review on detonation gun sprayed coatings, J. Miner. Mater. Charact. Eng. 11 (2012) 243-265.

[4] J. Stokes, L. Looney, Residual stress in HVOF thermally sprayed thick deposits, Surf. Coatings Technol. 177-178 (2004) 18-23.

[5] D.U. Toma, W. Brandl, G. Marginean, Wear and corrosion behaviour of thermally sprayed cermet coatings, Surf. Coat. Technol. (2001) 149-158.

[6] D.K. Goyal, H. Singh, H. Kumar, V. Sahni, Slurry erosion behaviour of HVOF sprayed WC-10Co-4Cr and Al 20 3+13TiO 2 coatings on a turbine steel, Wear. 289 (2012) 4657.

[7] H. Assadi, F. Gärtner, T. Stoltenhoff, H. Kreye, Bonding mechanism in cold gas spraying, Acta Mater. 51 (2003) 4379-4394.

[8] G. Shayegan, H. Mahmoudi, R. Ghelichi, J. Villafuerte, J. Wang, M. Guagliano, et al., Residual stress induced by cold spray coating of magnesium AZ31B extrusion, Mater. Des. 60 (2014) 72-84.

[9] Y. Xiong, W. Zhuang, M. Zhang, Effect of the thickness of cold sprayed aluminium alloy coating on the adhesive bond strength with an aluminium alloy substrate, Surf. Coatings Technol. 270 (2015) 259-265.

[10] M. Yandouzi, E. Sansoucy, L. Ajdelsztajn, B. Jodoin, WC-based cermet coatings produced by cold gas dynamic and pulsed gas dynamic spraying processes, Surf. Coatings Technol. 202 (2007) 382-390.

[11] M. Couto, S. Dosta, M. Torrell, J. Fernández, J.M. Guilemany, Cold spray deposition of WC-17 and 12Co cermets onto aluminum, Surf. Coatings Technol. 235 (2013) 54-61.

[12] D. Seo, M. Sayar, K. Ogawa, SiO 2 and MoSi 2 formation on Inconel 625 surface via SiC coating deposited by cold spray, Surf. Coatings Technol. 206 (2012) 2851-2858.

[13] X.T. Luo, G.J. Yang, C.J. Li, Multiple strengthening mechanisms of cold-sprayed 
cBNp/NiCrAl composite coating, Surf. Coatings Technol. 205 (2011) 4808-4813.

[14] A.C. Hall, L.N. Brewer, T.J. Roemer, Preparation of aluminum coatings containing homogenous nanocrystalline microstructures using the cold spray process, J. Therm. Spray Technol. 17 (2008) 352-359.

[15] C. Borchers, F. Gärtner, T. Stoltenhoff, H. Assadi, H. Kreye, Microstructural and macroscopic properties of cold sprayed copper coatings, J. Appl. Phys. 93 (2003) 1006410070.

[16] H.J. Fecht, Nanostructure formation by mechanical attrition, Nanostructured Mater. 6 (1995) 33-42.

[17] C.J. Li, W.Y. Li, Y.Y. Wang, Formation of metastable phases in cold-sprayed soft metallic deposit, Surf. Coatings Technol. 198 (2005) 469-473.

[18] K. Kim, M. Watanabe, J. Kawakita, S. Kuroda, Grain refinement in a single titanium powder particle impacted at high velocity, Scr. Mater. 59 (2008) 768-771.

[19] S.K. Mishra, S. Biswas, A. Satapathy, A study on processing, characterization and erosion wear behavior of silicon carbide particle filled ZA-27 metal matrix composites, Mater. Des. 55 (2014) 958-965.

[20] Z. Zhang, D.L. Chen, Contribution of Orowan strengthening effect in particulatereinforced metal matrix nanocomposites, Mater. Sci. Eng. A. 483-484 (2008) 148-152.

[21] H. Gül, F. Kili, M. Uysal, S. Aslan, A. Alp, H. Akbulut, Effect of particle concentration on the structure and tribological properties of submicron particle $\mathrm{SiC}$ reinforced $\mathrm{Ni}$ metal matrix composite (MMC) coatings produced by electrodeposition, Appl. Surf. Sci. 258 (2012) 4260-4267.

[22] D.A. Stewart, P.H. Shipway, D.G. McCartney, Abrasive wear behaviour of conventional and nanocomposite HVOF-sprayed WC-Co coatings, Wear. 225-229 (1999) 789-798.

[23] B.W. Chua, L. Lu, M.O. Lai, Influence of SiC particles on mechanical properties of Mg based composite, Compos. Struct. 47 (1999) 595-601.

[24] A.M. Redsten, E.M. Klier, A.M. Brown, D.C. Dunand, Mechanical properties and microstructure of cast oxide-dispersion-strengthened aluminum, Mater. Sci. Eng. A. 201 (1995) 88-102.

[25] P.H. Shipway, D.G. McCartney, T. Sudaprasert, Sliding wear behaviour of conventional and nanostructured HVOF sprayed WC-Co coatings, Wear. 259 (2005) 820-827.

[26] Q. Fang, P. Sidky, M.. Hocking, Erosive wear behaviour of aluminium based composites, Mater. Des. 18 (1997) 389-393.

[27] A. Neville, F. Reza, S. Chiovelli, T. Revega, Erosion-corrosion behaviour of WC-based 
MMCs in liquid-solid slurries, in: Wear, 2005: pp. 181-195.

[28] L. Liu, J. Xu, A study of the erosion-corrosion behavior of nano-Cr2O 3 particles reinforced $\mathrm{Ni}$-based composite alloying layer in aqueous slurry environment, Vacuum. 85 (2011) 687-700.

[29] K.J. Hodder, H. Izadi, A.G. McDonald, A.P. Gerlich, Fabrication of aluminum-alumina metal matrix composites via cold gas dynamic spraying at low pressure followed by friction stir processing, Mater. Sci. Eng. A. 556 (2012) 114-121.

[30] A. Rahbar-kelishami, A. Abdollah-zadeh, M.M. Hadavi, R.A. Seraj, A.P. Gerlich, Improvement of wear resistance of sprayed layer on 52100 steel by friction stir processing, Appl. Surf. Sci. 316 (2014) 501-507.

[31] G. Rolland, P. Sallamand, V. Guipont, M. Jeandin, E. Boller, C. Bourda, Damage study of cold-sprayed composite materials for application to electrical contacts, J. Therm. Spray Technol. 21 (2012) 758-772.

[32] R. Miranda, J. Gandra, P. Vilaca, L. Quintino, T. Santos, Surface Modification by Solid State Processing, Woodhead Publishing Limited, 2008.

[33] R.S. Mishra, M.W. Mahoney, Friction stir welding and processing, Mater. Sci. Eng. R Reports. 50 (2007) 360.

[34] Y. Morisada, H. Fujii, T. Mizuno, G. Abe, T. Nagaoka, M. Fukusumi, Modification of thermally sprayed cemented carbide layer by friction stir processing, Surf. Coatings Technol. 204 (2010) 2459-2464.

[35] T. Peat, A. Galloway, T. Marrocco, N. Iqbal, Microstructural Evaluation of Cold Spray Deposited WC with Subsequent Friction Stir Processing, Frict. Stir Weld. Process. VIII. (2015).

[36] C. Huang, W. Li, Z. Zhang, M. Fu, M. Planche, H. Liao, et al., Modification of a cold sprayed SiCp/AI5056 composite coating by friction stir processing, Surf. Coatings Technol. 296 (2016) 69-75.

[37] S. Turenne, M. Fiset, J. Masounave, The effect of sand concentration on the erosion of materials by a slurry jet, Wear. 133 (1989) 95-106.

[38] S.S. Rajahram, T.J. Harvey, R.J.K. Wood, Erosion-corrosion resistance of engineering materials in various test conditions, Wear. 267 (2009) 244-254.

[39] C.J. Lee, J.C. Huang, P.J. Hsieh, Mg based nano-composites fabricated by friction stir processing, Scr. Mater. 54 (2006) 1415-1420.

[40] A. Toumpis, A. Galloway, S. Cater, N. McPherson, Development of a process envelope for friction stir welding of DH36 steel - A step change, Mater. Des. 62 (2014) 64-75. 
[41] S.R. Sharma, Z.Y. Ma, R.S. Mishra, Effect of friction stir processing on fatigue behavior of A356 alloy, Scr. Mater. 51 (2004) 237-241.

[42] Z.Y. Ma, S.R. Sharma, R.S. Mishra, Effect of multiple-pass friction stir processing on microstructure and tensile properties of a cast aluminum-silicon alloy, Scr. Mater. 54 (2006) 1623-1626.

[43] B. Fiedler, F.H. Gojny, M.H.G. Wichmann, M.C.M. Nolte, K. Schulte, Fundamental aspects of nano-reinforced composites, Compos. Sci. Technol. 66 (2006) 3115-3125.

[44] R. Bauri, D. Yadav, G. Suhas, Effect of friction stir processing (FSP) on microstructure and properties of Al-TiC in situ composite, Mater. Sci. Eng. A. 528 (2011) 4732-4739.

[45] H.S. Arora, H. Singh, B.K. Dhindaw, Wear behaviour of a Mg alloy subjected to friction stir processing, Wear. 303 (2013) 65-77.

[46] Y. Chen, H. Ding, J. Li, Z. Cai, J. Zhao, W. Yang, Influence of multi-pass friction stir processing on the microstructure and mechanical properties of Al-5083 alloy, Mater. Sci. Eng. A. 650 (2016) 281-289.

[47] M. Kouzeli, A. Mortensen, Size dependent strengthening in particle reinforced aluminium, 50 (2002) 39-51.

[48] H.S. Khare, D.L. Burris, A quantitative method for measuring nanocomposite dispersion, Polymer (Guildf). 51 (2010) 719-729.

[49] M. Yourdkhani, P. Hubert, Quantitative dispersion analysis of inclusions in polymer composites, ACS Appl. Mater. Interfaces. 5 (2013) 35-41.

[50] Z.P. Luo, J.H. Koo, Quantification of the layer dispersion degree in polymer layered silicate nanocomposites by transmission electron microscopy, Polymer (Guildf). 49 (2008) 1841-1852.

[51] K. Sugiyama, S. Nakahama, S. Hattori, K. Nakano, Slurry wear and cavitation erosion of thermal-sprayed cermets, Wear. 258 (2005) 768-775.

[52] H.M. Hawthorne, B. Arsenault, J.P. Immarigeon, J.G. Legoux, V.R. Parameswaran, Comparison of slurry and dry erosion behaviour of some HVOF thermal sprayed coatings, Wear. 225-229 (1999) 825-834.

[53] H.S. Grewal, H.S. Arora, H. Singh, a. Agrawal, Surface modification of hydroturbine steel using friction stir processing, Appl. Surf. Sci. 268 (2013) 547-555.

[54] S. Dodds, A.H. Jones, S. Cater, Tribological enhancement of AISI 420 martensitic stainless steel through friction-stir processing, Wear. 302 (2013) 863-877.

[55] I. Finnie, Erosion of surfaces by solid particles, Wear. 3 (1960) 87-103.

[56] Z.B. Zheng, Y.G. Zheng, W.H. Sun, J.Q. Wang, Erosion-corrosion of HVOF-sprayed Fe- 
based amorphous metallic coating under impingement by a sand-containing $\mathrm{NaCl}$ solution, Corros. Sci. 76 (2013) 337-347.

[57] N. Andrews, L. Giourntas, A.M. Galloway, A. Pearson, Effect of impact angle on the slurry erosion-corrosion of Stellite 6 and SS316, Wear. 320 (2014) 143-151.

[58] W. Wu, K.C. Goretta, J.L. Routbort, Erosion of 2014 Al reinforced with $\mathrm{SiC}$ or Al2O3 particles, Mater. Sci. Eng. A. 151 (1992) 85-95.

[59] M.R. Ramesh, S. Prakash, S.K. Nath, P.K. Sapra, B. Venkataraman, Solid particle erosion of HVOF sprayed WC-Co/NiCrFeSiB coatings, Wear. 269 (2010) 197-205. 